


\section{U.S. Geological Survey Science Strategy for the Wyoming Landscape Conservation Initiative}

By Zachary H. Bowen, Cameron L. Aldridge,

Patrick J. Anderson, Geneva W. Chong, Mark A. Drummond,

Collin Homer, Ronald C. Johnson, Matthew J. Kauffman,

Steven T. Knick, John J. Kosovich, Kirk A. Miller, Tom Owens,

Sarah Shafer, and Michael J. Sweat

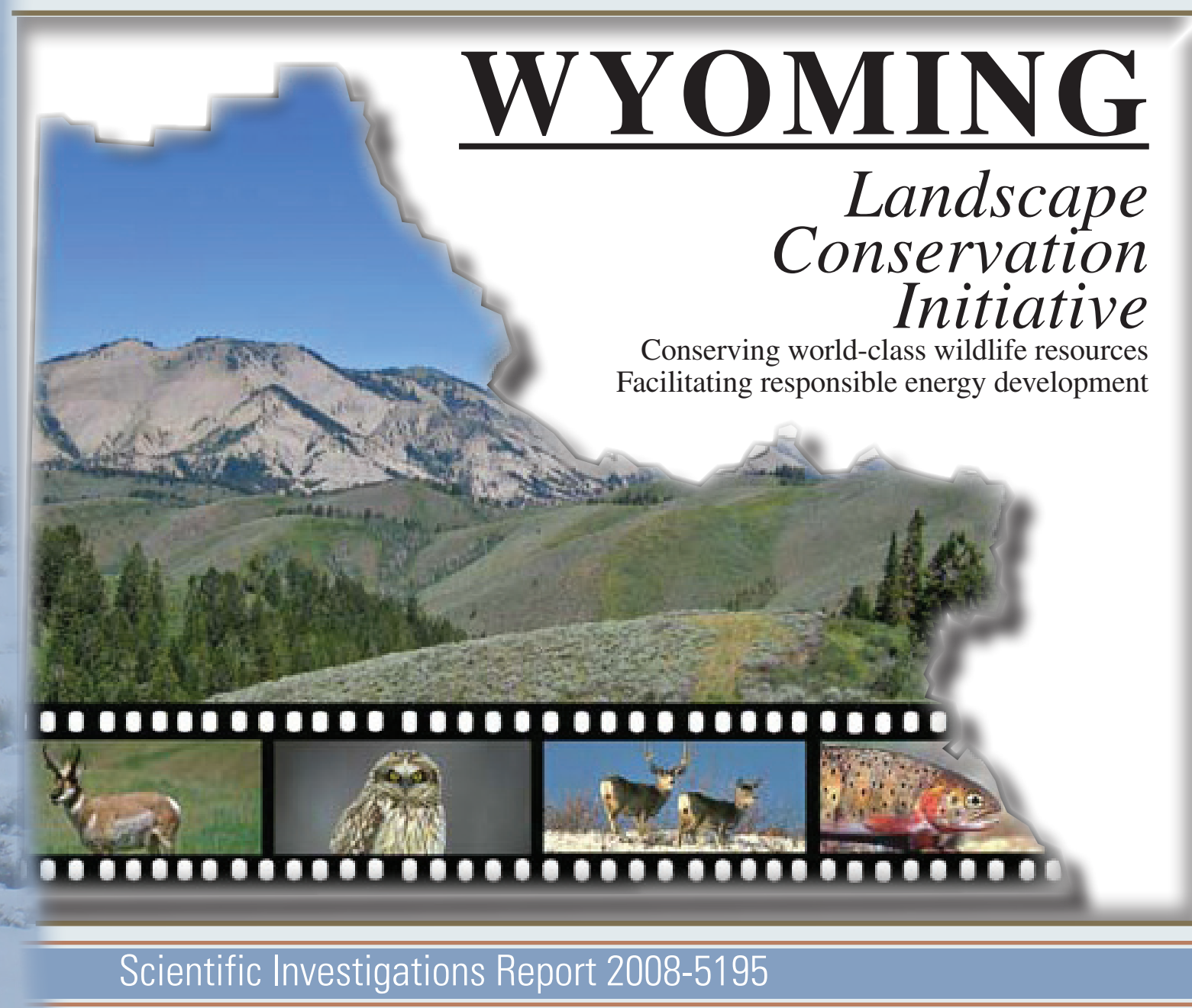

U.S. Department of the Interior

U.S. Geological Survey 


\section{U.S. Department of the Interior KEN SALAZAR, Secretary}

\section{U.S. Geological Survey \\ Suzette M. Kimball, Acting Director}

U.S. Geological Survey, Reston, Virginia: 2009

This and other USGS information products are available at http://store.usgs.gov/

U.S. Geological Survey

Box 25286, Denver Federal Center

Denver, CO 80225

To learn about the USGS and its information products visit http://www.usgs.gov/ 1-888-ASK-USGS

Any use of trade, product, or firm names is for descriptive purposes only and does not imply endorsement by the U.S. Government.

Although this report is in the public domain, permission must be secured from the individual copyright owners to reproduce any copyrighted materials contained within this report.

\section{Suggested Citation:}

Bowen, Z.H., Aldridge, C.L.., Anderson, P.J., Chong, G.W., Drummond, M.A., Homer, C., Johnson, R.C., Kauffman, M.J., Knick, S.T., Kosovich, J.J., Miller, K.A., Owens, T., Shafer, S., and Sweat, M.J., 2009,

U.S. Geological Survey Science Strategy for the Wyoming Landscape Conservation Initiative:

U.S. Geological Survey Scientific Investigations Report 2008-5195, 26 p.
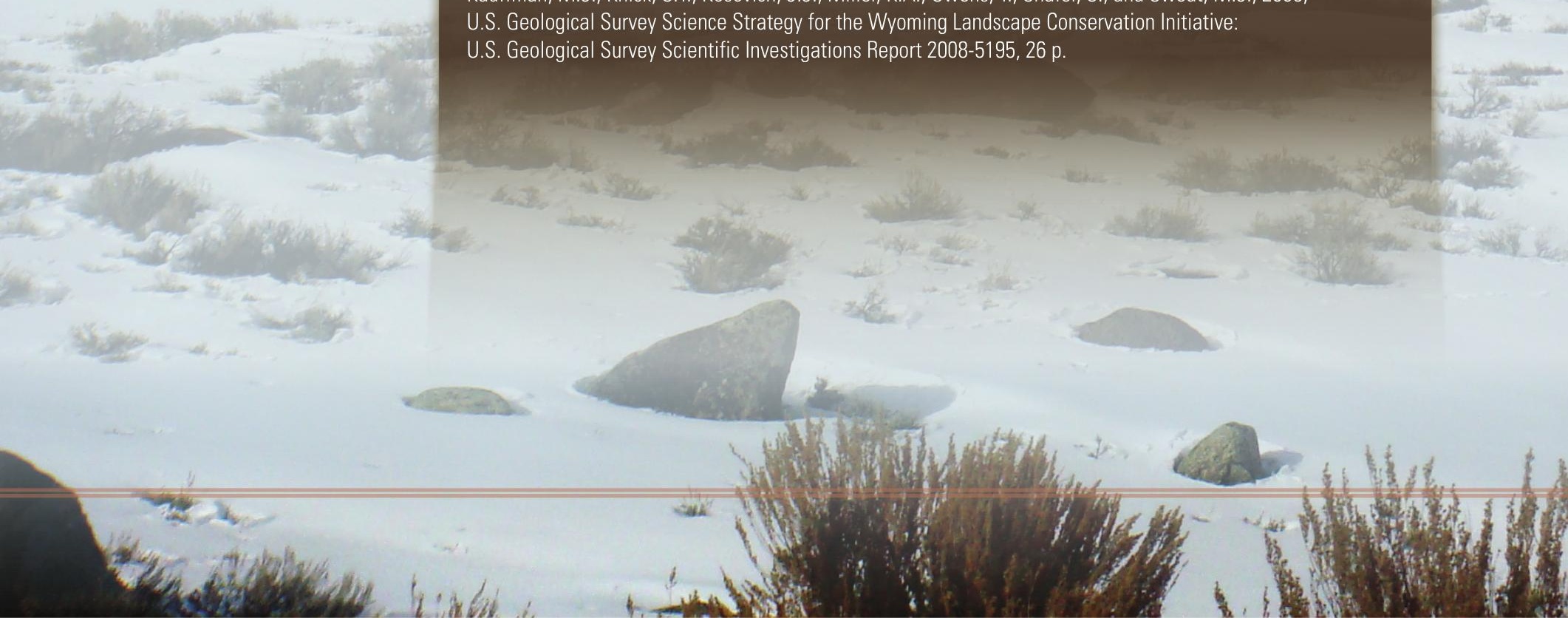


\section{Contents}

Abstract

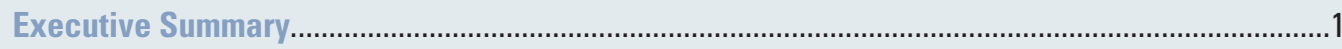

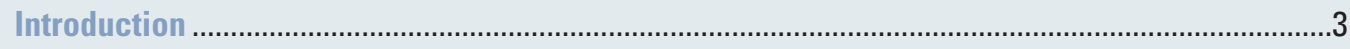

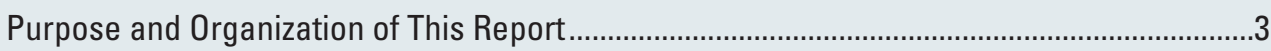

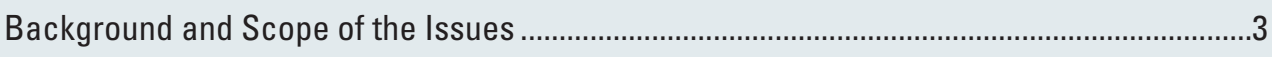

Energy Development in Wyoming .................................................................................

Importance of Natural Resources in Southwest Wyoming .............................................

WLCI Goal and Strategies Will Complement Existing Conservation Efforts ...............................5

WLCI Implementation and Science Strategy Development .....................................................5

USGS WLCI Science Team Goals, Philosophy, and Basic Premises .................................7

Major Components and Review of the USGS WLCI Science Strategy..............................7

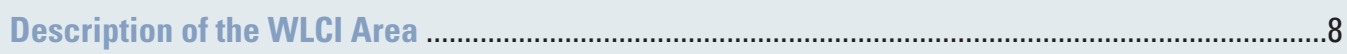

Geographic Area

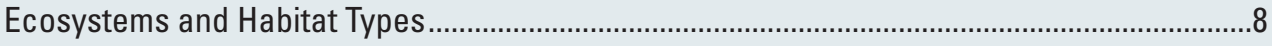

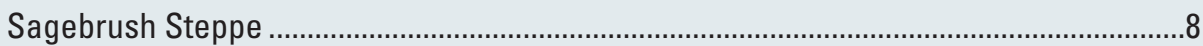

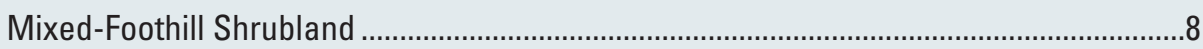

Aspen .

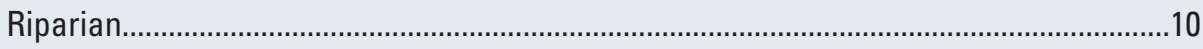

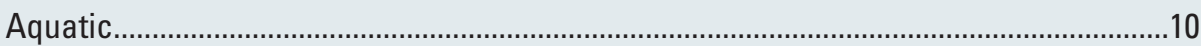

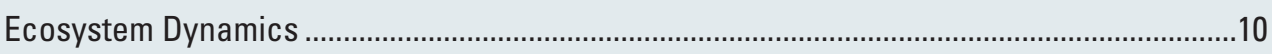

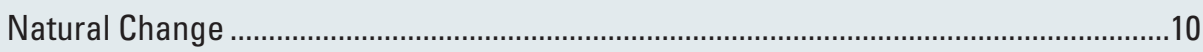

Anthropogenic Change ............................................................................................

The Interactive Effects of Natural and Anthropogenic Changes ....................................10

\section{WLCI Management Needs for Evaluating Cumulative Environmental}

Effects of Development Activities in Southwest Wyoming ...............................................11

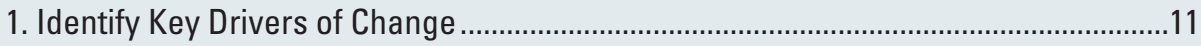

Objectives for Addressing Management Need 1 ..................................................12

Short-Term Activities for Meeting Objectives...........................................................12

Long-Term Activities for Meeting Objectives..........................................................13

2. Identify Condition and Distribution of Key Wildlife Species,

Habitats, and Species Habitat Requirements.....................................................13

Objectives for Addressing Management Need 2 ………........................................13

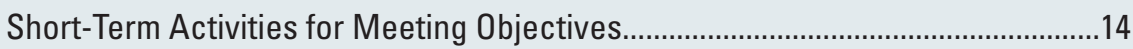

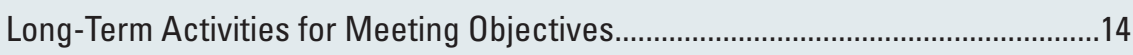

3. Evaluate Wildlife and Livestock Responses to Development ........................................14

Objectives for Addressing Management Need 3 …….........................................

Short-Term Activities for Meeting Objectives.......................................................15

Long-Term Activities for Meeting Objectives..........................................................15 
4. Evaluate the Effectiveness of Restoration, Reclamation, and Mitigation Activities

Objectives for Addressing Management Need 4 ………….................................16

Short-Term Activities for Meeting Objectives..........................................................16

Long-Term Activities for Meeting Objectives.......................................................16

5. Develop an Integrated Inventory and Monitoring Strategy........................................17

Objectives for Addressing Management Need 5 ..................................................17

Short-Term Activities for Meeting Objectives..........................................................18

Long-Term Activities for Meeting Objectives.........................................................18

6. Develop a Data Clearinghouse and Information-Management

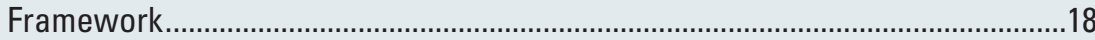

Objectives for Addressing Management Need 6 …………...................................18

Short-Term Activities for Meeting Objectives........................................................19

Long-Term Activities for Meeting Objectives........................................................19

Research and Monitoring Approaches ........................................................................................19

Range of Approaches Proposed for WLCI Science.........................................................

Retrospective Studies ...........................................................................................19

Treatment and Control Studies .....................................................................................19

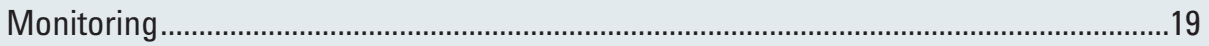

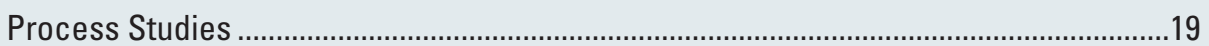

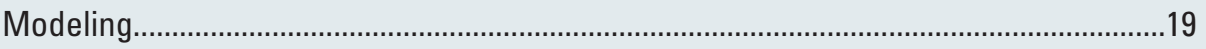

Optimizing Adaptive Management Through a Coordinated Research

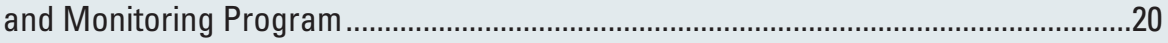

Developing a Framework for Conducting WLCI Science........................................................21

Implementation of the USGS WLCI Science Strategy ................................................................22

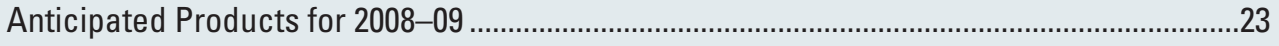

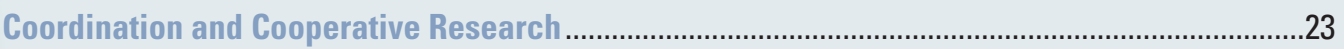

Education, Outreach, and Community Involvement ..........................................................................24

References Cited

\section{Figures}

1. Graph showing past, present, and projected gas production in Wyoming....

2. Map of the Wyoming Landscape Conservation Initiative area showing surface jurisdiction.

3. Illustration of the adaptive management cycle. ……………………………………….......20

4. Illustration showing a three-phase approach to monitoring ecosystem components. 


\section{Conversion Factors}

\section{Inch/Pound to SI}

\begin{tabular}{lll}
\hline Multiply & By & To obtain \\
\hline & Length & \\
inch (in.) & 2.54 & centimeter $(\mathrm{cm})$ \\
foot (ft) & 0.3048 & meter $(\mathrm{m})$ \\
mile (mi) & 1.609 & kilometer $(\mathrm{km})$ \\
\hline & Area & \\
acre & 0.4047 & hectare (ha) \\
acre & 0.004047 & square kilometer $\left(\mathrm{km}^{2}\right)$ \\
& Volume & \\
cubic foot $\left(\mathrm{ft}^{3}\right)$ & 0.02832 & cubic meter $\left(\mathrm{m}^{3}\right)$ \\
\hline
\end{tabular}

\section{Acronyms}

BLM - U.S. Bureau of Land Management

BMP - Best management practice

CWCS - Wyoming's Comprehensive Wildlife Conservation Strategy

DOI - Department of the Interior

FGDC - Federal Geographic Data Committee

FWS - U.S. Fish and Wildlife Service

I\&M - Inventory and monitoring

JIO - Jonah Interagency Mitigation and Reclamation Office

NEPA - National Environmental Policy Act

NPS — National Park Service

NSSI — North Slope Science Initiative

SGCN - Species of Greatest Conservation Need

STAC - Science and Technical Advisory Committee (of WLCI)

USFS - U.S. Forest Service

USGS - U.S. Geological Survey

WBEA - Wyoming Basins Ecoregional Assessment

WGFD - Wyoming Game and Fish Department

WLCI - Wyoming Landscape Conservation Initiative 


\section{By Zachary H. Bowen', Cameron L. Aldridge ${ }^{1,2}$, Patrick J. Anderson', Geneva W. Chong ${ }^{3}$, Mark A. Drummond ${ }^{1}$, Collin Homer ${ }^{4}$, Ronald C. Johnson ${ }^{5}$, Matthew J. Kauffman ${ }^{6}$, Steven T. Knick ${ }^{7}$, John J. Kosovich ${ }^{8}, K_{i r k}$ A. Miller ${ }^{9}$, Tom Owens ${ }^{10}$, Sarah Shafer ${ }^{11}$, and Michael J. Sweat ${ }^{9}$}

\section{Abstract}

Southwest Wyoming's wildlife and habitat resources are increasingly affected by energy and urban/exurban development, climate change, and other key drivers of ecosystem change. To ensure that southwest Wyoming's wildlife populations and habitats persist in the face of development and other changes, a consortium of public resource-management agencies proposed the Wyoming Landscape Conservation Initiative (WLCI), the overall goal of which is to implement conservation actions. As the principal agency charged with conducting WLCI science, the U.S. Geological Survey (USGS) has developed a Science Strategy for the WLCI. Workshops were held for all interested parties to identify and refine the most pressing management needs for achieving WLCI goals. Research approaches for addressing those needs include developing conceptual models for understanding ecosystem function, identifying key drivers of change affecting WLCI ecosystems, and conducting scientific monitoring and experimental studies to better understand ecosystems processes, cumulative effects of change, and effectiveness of habitat treatments. The management needs drive an iterative, three-phase framework developed for structuring and growing WLCI science efforts: Phase I entails synthesizing existing information to assess current conditions, determining what is already known about WLCI ecosystems, and providing a foundation for future work; Phase II entails conducting targeted research and monitoring to address gaps in data and knowledge during Phase I; and Phase III entails integrating new knowledge into WLCI activities and coordinating WLCI partners and collaborators. Throughout all three phases, information is managed and made accessible to interested parties and used to guide and improve management and conservation actions, future habitat treatments, best management practices, and other conservation activities.

\section{Executive Summary}

Southwest Wyoming has tremendous wildlife and habitat resources that are increasingly affected by multiple factors, including energy development, urban and exurban development, and climate change. The direct and interactive effects of these and other key drivers of ecosystem change must be understood thoroughly if land managers are to implement effective management and conservation actions in the region. In response to this need, a group of Federal and State agencies (hereafter, "partners") proposed the Wyoming Landscape Conservation Initiative (WLCI), a long-term, science-based effort. Additional WLCI participants (hereafter,

${ }^{1}$ U.S. Geological Survey, Fort Collins Science Center, Fort Collins, Colo.

${ }^{2}$ Natural Resource Ecology Laboratory, Colorado State University, Fort Collins, Colo.

${ }^{3}$ U.S. Geological Survey, Northern Rocky Mountain Science Center, Jackson, Wyo.

${ }^{4}$ U.S. Geological Survey, Earth Resources Observation and Science Data Center, Sioux Falls, S.D.

${ }^{5}$ U.S. Geological Survey, Central Energy Resources Team, Lakewood, Colo.

${ }^{6}$ U.S. Geological Survey, and Wyoming Cooperative Fish and Wildlife Research Unit, University of Wyoming, Laramie, Wyo.

${ }^{7}$ U.S. Geological Survey, Forest and Rangeland Ecosystem Science Center, Snake River Field Station, Boise, Idaho

${ }^{8}$ U.S. Geological Survey, Central Region Geospatial Information Office, Lakewood, Colo.

${ }^{9}$ U.S. Geological Survey, Wyoming Water Science Center, Cheyenne, Wyo.

${ }^{10}$ U.S. Geological Survey, Rocky Mountain Geographical Science Center, Denver, Colo.

${ }^{11}$ U.S. Geological Survey, Central Region Earth Surface Processes Team, Corvallis, Oreg.

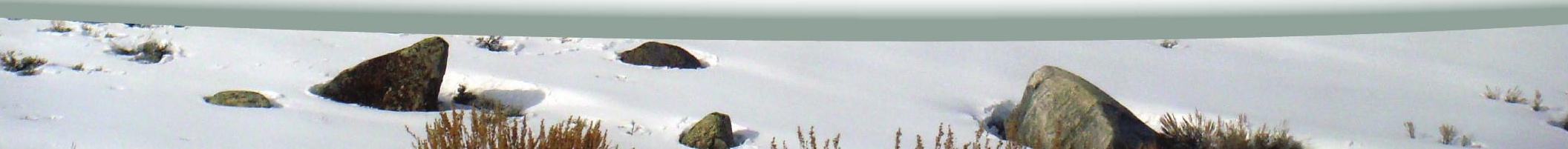




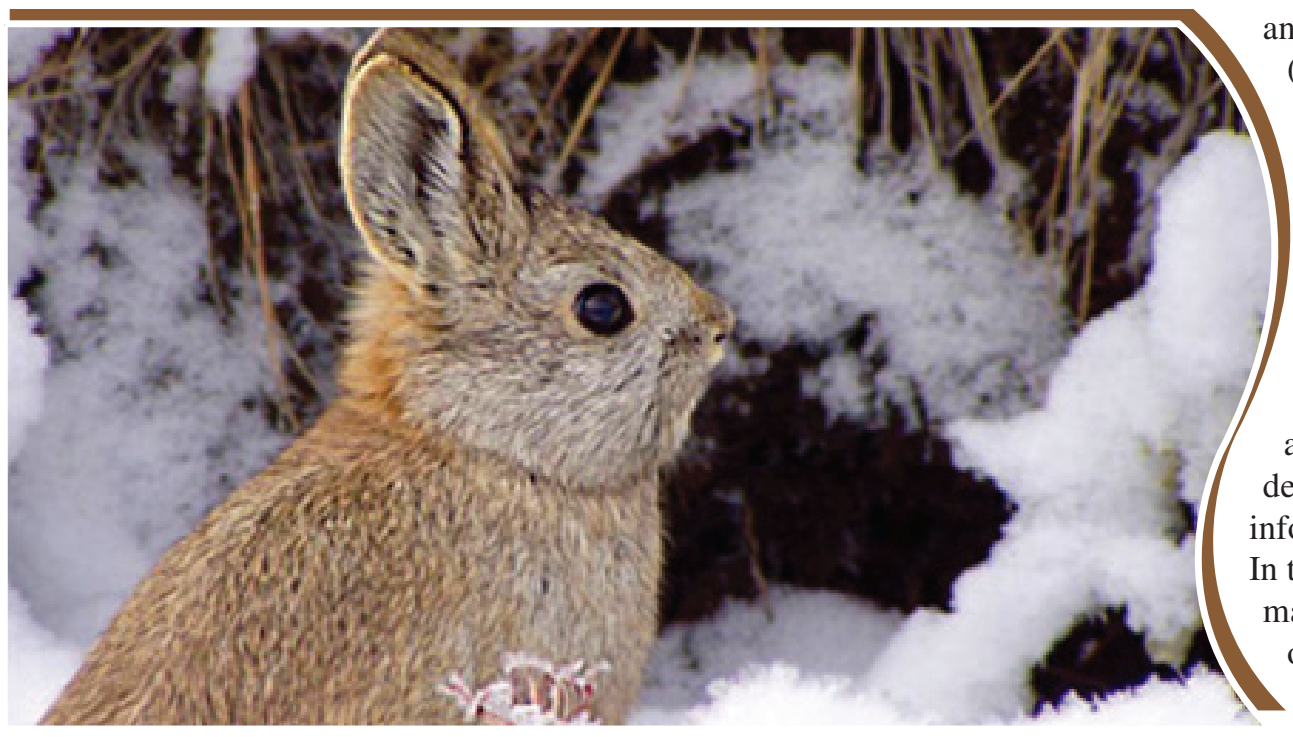

and species habitat requirements;

(3) evaluate wildlife and livestock

responses to energy and associated development; (4) identify the most effective and needed restoration, reclamation, and mitigation activities, as well as locations where conservation benefits may be maximized; (5) develop an integrated inventory and monitoring strategy; and (6) develop a data clearinghouse and information management framework. In the discussion provided for each management need, associated objectives and both the short- and long-term research needs for achieving those objectives are described.

"collaborators") include many public, nonprofit, and private organizations, and private landowners. The overall goal of the WLCI is to ensure that southwest Wyoming's wildlife populations and habitats persist in the face of increasing energy development and other land-use changes. The issues and goals associated with the WLCI effort align well with the U.S. Geological Survey's (USGS) science strategy directions of understanding ecosystems, climate variability and change, and energy and mineral resources, as well as conducting a water census of the United States (U.S. Geological Survey, 2007).

The principal goals of USGS WLCI science are to provide multidisciplinary scientific and technical support to WLCI partners and advance the overall scientific understanding of southwest Wyoming's ecosystems. Accomplishing these goals will entail (1) evaluating the effectiveness of habitat treatments implemented by WLCI partners and collaborators, and (2) assessing the cumulative effects of energy development and other land-use changes in the WLCI area. Information gained from both areas of research will then be used to guide and improve future habitat treatments, best management practices, and other conservation activities. Most of the WLCI science will be developed and conducted by a team of USGS scientists, who will provide multidisciplinary scientific and technical support to the WLCI partners. The purpose of this report, therefore, is to outline the USGS WLCI team's strategy (hereafter "Strategy") for conducting WLCI science. Each fiscal year (FY), the detailed scopes of work and expected products for WLCI science will be outlined in a separate document.

To help build an effective science program of research and monitoring for the WLCI, workshops were held for WLCI partners and collaborators to identify and refine the most pressing needs for implementing effective management and conservation actions. The six management needs are to (1) identify the key drivers of change; (2) identify the condition and distribution of key wildlife species, habitat,
Research approaches for addressing WLCI management needs will include developing conceptual models for understanding ecosystem function, identifying key drivers of change affecting WLCI ecosystems, and conducting experimental treatment and control studies, as well as retrospective analyses, process studies, and monitoring. An iterative, three-phase framework was developed for structuring and growing WLCI science efforts. Phase I of the framework entails conducting a baseline synthesis to determine what is already known about WLCI ecosystems and providing a foundation for future work. Phase II entails conducting targeted research and monitoring to address gaps in data and knowledge that builds on the foundation developed through the baseline synthesis. Phase III involves integrating new knowledge into WLCI activities and coordination among WLCI partners and collaborators. The three phases are intended to be iterative, building continuously upon what has already been learned.

The human-dimension aspects of WLCI also are crucial to the program's overall success. Whereas detailed approaches to coordinating WLCI as a whole are discussed in other documents (see http://www.wlci.gov/), the Strategy summarizes USGS approaches for ensuring cooperation and coordination among WLCI partners and collaborators; informing WLCI partners, collaborators, and the general public about WLCI activities; and providing opportunities for involvement with respect to WLCI science. These approaches entail taking full advantage of electronic media (the Internet in particular) for cataloging, displaying, and communicating WLCI results and products, as well as public presentations and various publication outlets. In addition, there have been and will continue to be frequent meetings and workshops to gather the full spectrum of perspectives and ideas, provide educational opportunities, and foster involvement. These efforts will go a long way towards achieving the overall goal of the WLCI program as well as the USGS WLCI science goals. 


\section{Introduction}

\section{Purpose and Organization of This Report}

The recent surge of energy development in southwest Wyoming and its potential effects on the region's wildlife led the U.S. Bureau of Land Management and the Wyoming Department of Game and Fish to conceptualize a landscapelevel initiative to address their concerns. This initiative is the Wyoming Landscape Conservation Initiative (WLCI; see http://www.wlci.gov/) for southwest Wyoming. WLCI partners (agencies that signed a memorandum of understanding [MOU] regarding their roles and intent in the WLCI) include the U.S. Bureau of Land Management (BLM), U.S. Geological Survey (USGS), U.S. Fish and Wildlife Service (FWS), Wyoming Game and Fish Commission, Wyoming Department of Agriculture, U.S. Forest Service (USFS), southwest Wyoming county commissioners, and southwest Wyoming conservation districts. Additional collaborators (interested organizations and parties not part of the WLCI partner MOU) providing support to the WLCI effort include many public, nonprofit, and private entities, including the National Park Service (NPS), U.S. Department of Agriculture Natural Resources Conservation Service, U.S. Bureau of Reclamation, Wyoming Department of Environmental Quality, Wyoming State Land Board, Jonah Interagency Mitigation and Reclamation Office (JIO), private industry, landowners, and nongovernment organizations and conservation groups.

This report, the USGS WLCI Science Strategy (hereafter the "Strategy"), presents the USGS strategy for WLCI science to be developed and conducted by a team of USGS scientists in collaboration with other WLCI partners and collaborators. Alaska's North Slope Science Initiative (NSSI; Krummel and LaGory, 2004) served as a model for the Strategy in terms of implementing a landscape-scale, science-based, long-term, cooperative program to ensure persistence and viability of world-class wildlife resources and habitats in the face of increasing energy development and other land-use changes. Unlike the NSSI, however, the WLCI has the added component of on-the-ground conservation activities, which will be refined and improved as new knowledge is gained through science and applied via adaptive management. The principal goals of USGS WLCI science are to provide multidisciplinary scientific and technical support to WLCI partners and collaborators, and to advance the overall scientific understanding of southwest Wyoming's ecosystems. Achieving goals will entail evaluating both (1) the effectiveness of habitat treatments implemented by WLCI partners and collaborators, and (2) the effects of energy development and other land-use changes. The knowledge and expertise gained from these science activities will be used to guide and improve the effectiveness of future habitat treatments, best management practices, mitigation activities, and placement of conservation areas. The Strategy also exemplifies the role that USGS plays on regional, national, and international levels in providing information on ecosystems and resource development, as outlined in the agency's overall science strategy document, Facing Tomorrow's Challenges (U.S. Geological Survey, 2007).

The Strategy is organized into six sections: (1) background information regarding the goal, strategies, and implementation that pertain specifically to the WLCI, as well as the goals, philosophies, and basic premises of USGS science for the WLCI; (2) a description of the WLCI area; (3) details of the six most pressing management needs identified by WLCI partners and collaborators; (4) proposed approaches to research and monitoring; (5) strategies for WLCI implementation, including cooperation and coordination among WLCI partners and collaborators; and (6) approaches for conducting education, outreach, and community involvement for the WLCI. Overall, the management needs are designed to focus WLCI science efforts and facilitate analyses of the cumulative effects associated with energy development and other land-use changes. Sections four through six make up the bulk of the Strategy. The annual plans or scopes of work proposed by USGS for WLCI science will be outlined in a separate document each fiscal year (FY) to provide a framework for the following year and build on information gained in prior years. The Strategy, also a living document, will be updated and amended as needed.

\section{Background and Scope of the Issues}

\section{Energy Development in Wyoming}

The Greater Green River Basin, which encompasses most of southwest Wyoming, as well as portions of northwestern Colorado and northeastern Utah, is one of five geologic basins that contain the majority of natural gas reserves in the 48 contiguous United States (U.S. Departments of Interior, Agriculture, and Energy, 2006). The 15-million-acre southwest Wyoming portion of the basin - roughly the size of Connecticut, Delaware, Massachusetts, and New Hampshire combined - contains an estimated 85 trillion cubic feet of recoverable natural gas, making it one of the Nation's largest concentrations of this resource and capable of contributing significantly to the demand for approximately 23 trillion cubic feet of natural gas used annually in the United States (U.S. Department of Energy, 2004). By the early 2000s, enough natural gas was being produced annually from the Greater Green River Basin to heat four million homes.

Development of energy resources in Wyoming began in the late 19th century (Mackey, 1997) and continued

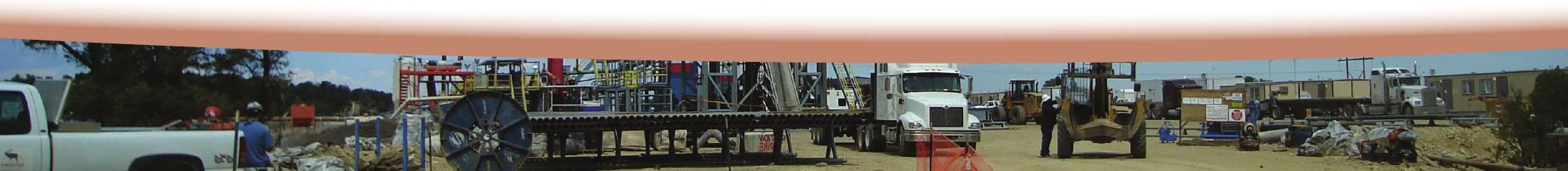


sporadically through the 20 th century. By early 2007 , there were more than 49,000 producing wells in the State, with another 17,000 forecasted to be drilled by 2010 (depending on Environmental Impact Statement processes; from Wyoming Oil and Gas Conservation Commission at http://wogcc.state. wy.us/). A substantial number of these forecasted energy developments will occur in the Greater Green River Basin of southwest Wyoming. Although Wyoming has long been a provider of the Nation's energy, the recent and projected pace of energy development is unprecedented in Wyoming's history (fig. 1).

Combined with increased residential and industrial development, fast-paced energy development is resulting in notable habitat loss and degradation, including habitat fragmentation due to road construction, increased traffic (industrial and residential), drilling rigs and well pads, service units, pipelines, power lines, fencing, water pits, water wells, increased human activity, and dust, among other impacts (Sawyer and others, 2006). Although studies are currently underway to address potential direct and indirect effects of energy development on terrestrial and aquatic wildlife species and habitats in Wyoming, in general little is known about the cumulative effects of intensive energy-extraction activities on the integrity of habitats or population viability of sagebrush obligates and species of concern, or how those activities alter agricultural practices, human population demographics, local governance, or recreation activities. Land-use planning and decisionmaking become increasingly complex when energy developments are considered along with other significant landuse activities, such as livestock grazing and recreation, and the effects of invasive plant species and climate change. Given the large proportion of publicly owned lands, the pattern of private land ownership, and the spatial distribution of existing and projected oil and gas development, decisions on landuse management in southwest Wyoming will substantially influence the persistence of the region's fish and wildlife, with regard to both species in general and species with special status.

\section{Importance of Natural Resources in Southwest Wyoming}

Southwest Wyoming encompasses some of the highestquality terrestrial and aquatic wildlife habitats in the Intermountain West (Sawyer and others, 2005). Sagebrush, mountain shrub, aspen, riparian, and aquatic habitats are crucial for a diversity of game and nongame species. The extensive landscapes dominated by sagebrush in this area support some of the largest extant populations of sagebrush-

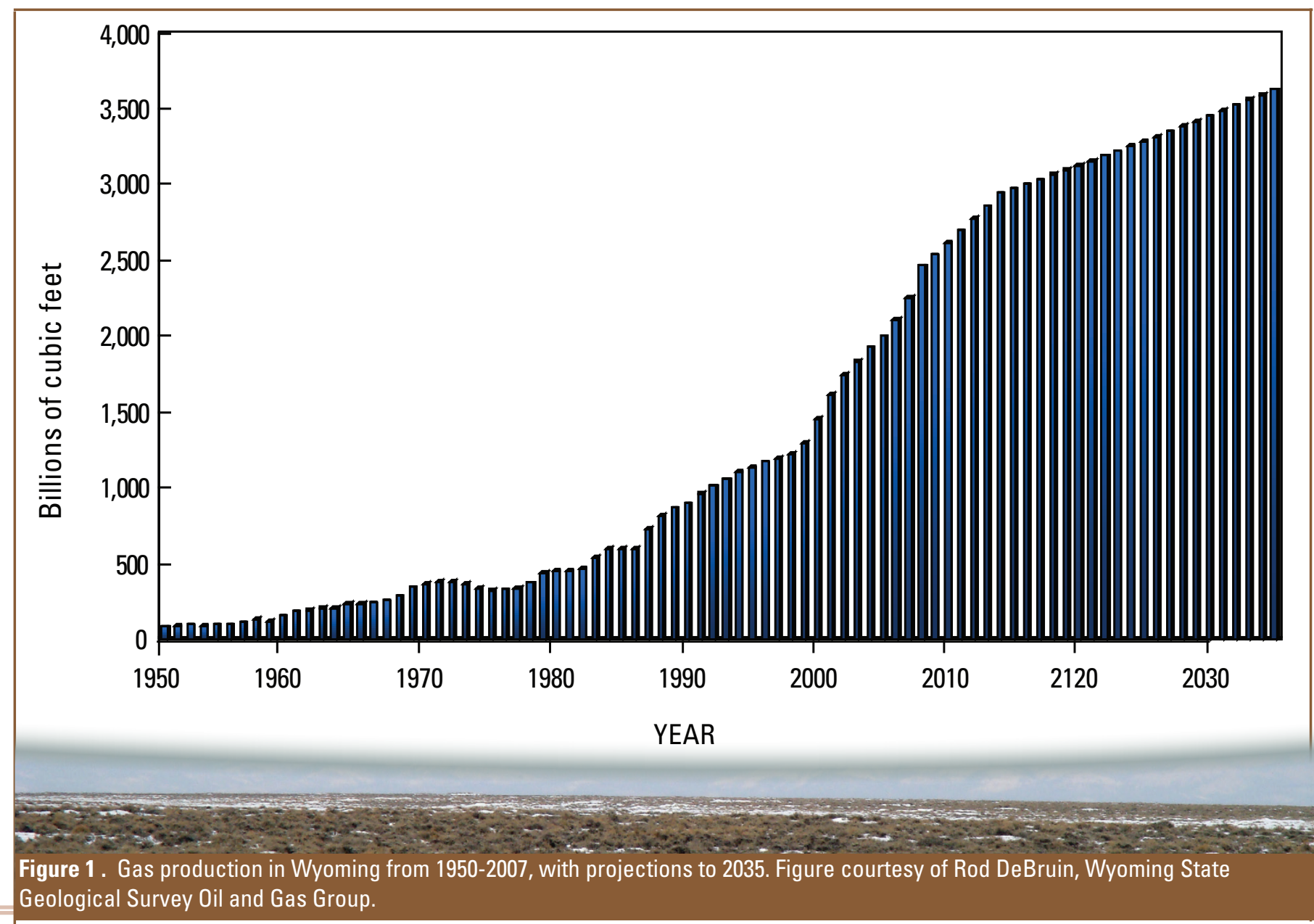


associated species in the United States, including greater sage-grouse (Centrocercus urophasianus) and pronghorn (Antilocarpa americana; Clark and Stromberg, 1987; Connelly and others, 2004). Estimated populations of wildlife in southwest Wyoming include 100,000 pronghorn and the highest density of greater sage-grouse within the species' range, as well as 100,000 mule deer (Odocoileus hemionus), 40,000 elk (Cervus elaphus), 8,000 moose (Alces alces), and 140 bighorn sheep (Ovis canadensis). The area also supports 151 native species, including three subspecies of native cutthroat trout (Oncorhynchus clarki bouvieri, O. c. pleuriticus, and O. c. utah), designated as "Species of Greatest Conservation Need" because their populations and habitats are declining or there is a lack of information about their status and distributions (see http://gf.state.wy.us/wildlife/ CompConvStrategy/SectionI.pdf and http://gf.state.wy.us/ wildlife/CompConvStrategy/CWCSSpeciesList050505.pdf for a species list and methods used to rank species; Wyoming Game and Fish Department, 2005). Climate change models for the sagebrush ecosystem predict that the largest area of sagebrush to persist in the future is the area between the northern and central Rocky Mountains in southern Wyoming (Neilson and others, 2005).

Southwest Wyoming's vast open spaces also support an important livestock industry represented by 1,400 familyowned farms and ranches, 119,000 cattle, and 95,000 sheep. These ranching and agricultural holdings help conserve these vast open spaces, which provide essential seasonal habitats and migration corridors for wildlife. Lands and water in southwest Wyoming also offer some of the country's most sought-after recreational opportunities, providing an important economic asset by attracting anglers, hunters, wildlife watchers, and other visitors seeking open spaces, majestic scenery, and outdoor recreation in natural settings. Based on average expenditures per recreational visitor day in Sublette, Sweetwater, and Lincoln Counties combined, the total annual revenue generated for outdoor recreation is $\$ 9.4$ million (TRC Mariah Associates, Inc., 2005; U.S. Bureau of Land Management, 2008). For many small rural communities, money spent by people seeking outdoor recreation is essential for long-term economic stability.

\section{WLCI Goal and Strategies Will Complement Existing Conservation Efforts}

To achieve the overall WLCI goal of ensuring that southwest Wyoming's terrestrial and aquatic habitats and wildlife populations persist in the face of increasing developments, WLCI partners and collaborators have proposed and are pursuing many strategies, including

- identifying areas of high wildlife-conservation value;

- developing and implementing effective monitoring strategies and protocols;
- applying adaptive management as indicated by monitoring trends and research results;

- facilitating data and information sharing between and among WLCI partners;

- providing guidelines for cooperating agencies, nongovernmental organizations, and other collaborators, including energy and livestock industries;

- making full use of interactive workshops, meetings, and electronic technologies to facilitate active involvement by public agencies, nongovernmental organizations, and the energy and livestock industries;

- establishing criteria for project selection and funding;

- implementing projects to help ensure that populations of important game and nongame species (including the Species of Greatest Conservation Need [SGCN] listed by Wyoming Game and Fish Department [http:// gf.state.wy.us/wildlife/CompConvStrategy/SectionI. $p d f$ ]; species designated by the FWS as Threatened or Endangered; and species considered economically or socially important) are sustained or improved; and

- developing best management practices (BMPs).

The WLCI is designed to help ensure that partners responsible for managing Wyoming's fish and wildlife and their habitats have the necessary information and resources for assessing the cumulative effects of anthropogenic activities and sustaining or improving habitat conditions, species distributions, and population viability at the landscape scale. It is not intended as an alternative or substitute for reclamation and mitigation actions required of industry, nor is it a replacement for existing efforts within the geographical area represented by the Strategy outlined in this report. Rather, development and implementation of WLCI strategies will complement and enhance existing efforts, including (but not limited to) those of local sage-grouse working groups, the Wyoming Basin Ecoregional Assessment (WBEA; Rowland and others, 2006), the Western Association of Fish and Wildlife Agencies' Greater Sage-Grouse and Sagebrush Habitats Conservation Strategy, BLM's National Assessment Inventory and Monitoring Strategy, and the FWS's Partners for Fish and Wildlife Program.

\section{WLCI Implementation and Science Strategy Development}

Implementation of all WLCI components, ranging from on-the-ground habitat projects (including, but not limited to, prescription burns, seeding, adding/removing/altering fences, and establishing conservation easements) to science (both 
research and monitoring), will require long-term funding for maintaining the necessary staff, as well as for planning and implementing the work. The WLCI partners identified four elements as critical for successful implementation of the initiative:

1. funding, staffing, and organizational planning to provide the means for supporting and implementing this effort;

2. a science strategy that identifies existing and additional information required for fish and wildlife habitat enhancement, species monitoring, and conservation work, as well as the research needed to determine whether reclamation projects successfully restore disturbed habitats to their predisturbance condition and processes/functions at various spatial and temporal scales;

3. an information management plan to facilitate data and information exchange within and amongst partners; and

4. a communication plan to share information with interested parties.

Although much of the background material, ideas, and approaches discussed herein will serve the broader planning needs of the WLCI, the Strategy is designed to address the second critical element listed above and briefly describe approaches to information management and communications, with an emphasis on USGS's role as a WLCI partner. It focuses on the management issues and related questions identified by WLCI partners and on expertise gained by USGS scientists from long-term experience working with land managers in Wyoming. Documents important to early development of the WLCI and the Strategy include the WLCI Concept Paper (Interagency Wyoming Landscape Conservation Initiative Planning Group, 2006), Wyoming's Comprehensive Wildlife Conservation Strategy (CWCS; Wyoming Game and Fish Department, 2005), the Wyoming Greater Sage-Grouse Conservation Plan (Wyoming Game and Fish Department, 2003), local working group plans, multiple BLM Planning documents, the WBEA (Rowland and others, 2006), and the overall science strategy developed for USGS (U.S. Geological Survey, 2007).

Efforts to define the most critical management needs associated with the WLCI included a series of meetings and workshops held in late 2006 and early 2007. Groups involved in these meetings included the WLCI Executive Committee (composed of government executives and elected officials to provide guidance and decisionmaking authority for the WLCI) and the WLCI Coordination Team (composed of interagency personnel responsible for managing the daily operations of the WLCI and maintaining regular contact with WLCI partners and collaborators at the field level; see http://www.wlci.gov/ docs/WLCI_MOU_Signed.pdf). In addition, there were open house meetings at BLM field offices and meetings with multiple WLCI partners and collaborators in the WLCI area. Through these interactions, participants developed and refined the six most pressing WLCI management needs for evaluating the cumulative effects of anthropogenic activities in southwest Wyoming:

(1) identify the key drivers of change;

(2) identify the condition and distribution of key wildlife species, habitat, and species' habitat requirements;

(3) evaluate wildlife and livestock responses to development;

(4) identify the most effective and needed restoration, reclamation, and mitigation activities, as well as locations where conservation benefits may be maximized;

(5) develop an integrated inventory and monitoring strategy; and

(6) develop a data clearinghouse and informationmanagement framework.

The Strategy focuses on these management needs, which are detailed in the WLCI management needs section, their objectives for addressing the management needs, and the priority short- and long-term activities (research and technical assistance) for meeting those objectives.

To gain additional perspectives on and information for the WLCI and associated management needs, a WLCI science workshop was held at the University of Wyoming in May 2007 and attended by 140 individuals representing over 35 different agencies or groups. Comprehensive notes and a workshop summary were compiled by the Ruckelshaus Institute (http:// $w w w . u w y o . e d u / E N R / I E N R /)$ to provide information useful for developing the USGS WLCI Science Strategy, subsequently published as a USGS Scientific Investigations Report (D'Erchia, 2008). The management needs (with the exception of number 4 above, which was added after the workshop) were deliberated during six plenary sessions and associated breakout sessions. There were several overlapping findings from the six sessions, which included the need to

- create a long-term, accessible information database;

- identify key habitats, indicator species, and umbrella species;

- identify gaps in baseline data and fill those gaps;

- begin on-the-ground projects (for example, fencing, planting, or other habitat improvements) as soon as possible; and 
- implement a monitoring program that provides information applicable to adaptive management goals.

Several overlapping concerns also expressed during the WLCI science workshop included

- how to secure adequate and long-term funding;

- how to manage the WLCI workload with understaffed agencies;

- how best to approach cumulative-effects assessment;

- the value and effectiveness of offsite mitigation;

- transitioning to on-the-ground adaptive management; and

- too much emphasis on research.

The WLCI science workshop affirmed the importance of the WLCI management needs, and participants provided additional expertise, experience, and many new ideas useful for enhancing the original management needs. Although some of the ideas and concerns identified fell outside the scope of the Strategy, all comments and ideas presented during the workshop and captured in the workshop proceedings provided important context for the Strategy. Whereas the Strategy embodies that larger context, it also provides enough specificity to direct near-term activities and refine plans as the initiative evolves; however, to distinguish the Strategy from the more detailed scope of work planned, annual scopes of work will be published separately.

\section{USGS WLCI Science Team Goals, Philosophy, and Basic Premises}

During its first meeting, the USGS WLCI Science Team (hereafter "Science Team") had the overall goals of developing (1) a research strategy for evaluating the effects of land-use change on ecosystems in southwest Wyoming, with an emphasis on energy development and how it interacts with other major drivers, such as climate, and (2) projects that provide information to support management decisions and promote an understanding of how to maintain ecosystem processes and function. To guide development of these Strategy elements and successfully integrate science with the overall WLCI effort, the group first established its science philosophy and a set of basic premises, both of which arose from the intersection of ideas that generated the WLCI and the mission and capabilities of USGS, as described in the overall USGS science strategy (U.S. Geological Survey, 2007). They represent important themes and considerations regarding the research and technical assistance projects in which USGS should engage. The philosophy adopted for WLCI science and technical assistance is that projects must integrate multiple collaborators and disciplines across various spatial and temporal scales. Basic premises include

- focusing on management needs;

- integrating existing data provided by WLCI partners and building on that knowledge;

- coordinating all plans and work activities with WLCI partners and collaborators;

- developing research and monitoring products suitable for adaptive management;

- advancing scientific understanding; and

- developing an applied research approach that is broadly applicable to other geographic areas.

\section{Major Components and Review of the USGS WLCI Science Strategy}

The subsequent sections of the Strategy, and the intent of each, are summarized below.

- Description of the WLCI Area delineates the WLCI boundaries and sets the stage for WLCI science by briefly describing the habitat types of southwest Wyoming identified as WLCI priorities and summarizing southwest Wyoming's ecosystem dynamics, both natural and anthropogenic, and their combined effects.

- WLCI Management Needs for Evaluating Cumulative Environmental Effects of Development Activities in Southwest Wyoming details the six most pressing management needs identified by WLCI partners and collaborators; it also lists the objectives for addressing each management need and the short- and long-term research and technical assistance activities proposed for meeting those objectives. The research objectives were identified during meetings of the Science Team and during the May 2007 WLCI science workshop (D’Erchia, 2008).

- Research and Monitoring Approaches briefly describes the spectrum of research and monitoring approaches that will be employed for the WLCI, including the development of conceptual models for identifying and illustrating key drivers of ecosystem change. It also describes an iterative, three-phase framework for developing and implementing specific WLCI research and technical assistance activities. The framework was based on a convergent set of ideas presented in documents on ecoregional assessment, research, and monitoring (summarized in Kotliar and others, 2008). 
- Implementation of the USGS WLCI Science Strategy indicates that a full-time USGS employee has been dedicated to the WLCI Coordination Team to assist with ongoing needs for technical assistance and to participate in selecting and coordinating BLM habitatimprovement projects implemented in 2007 and beyond.

- Coordination and Cooperative Research discusses how the set of USGS science activities described in prior sections will be linked to ongoing work by USGS and other entities.

- Education, Outreach, and Community Involvement provides a brief discussion of important tools, approaches, and activities needed to communicate findings and involve the public in the science of the WLCI.

The Strategy has undergone review for content, relevance to WLCI, and technical feasibility by the WLCI Science and Technical Advisory Committee (STAC; an interagency team set up to prioritize WLCI science and help apply science to on-the-ground management and conservation actions), the WLCI Executive Committee, and additional outside reviewers. All comments were considered carefully and incorporated to the extent possible. The Strategy was written for a 5-year research program; thus, it will be reviewed and refined as the WLCI evolves. It is also anticipated that the accompanying scope of work document will be reviewed annually by the STAC and updated.

\section{Description of the WLCI Area}

\section{Geographic Area}

The WLCI area, which encompasses the Wyoming portion of the Greater Green River Basin and the Great Divide Basin, is bounded by the northern edges of Wyoming's Lincoln and Sublette Counties, the Continental Divide, Colorado, Utah, and Idaho (fig. 2). The major basins encompassed by the WLCI boundaries are those of the Green, Snake, Bear, and White-Yampah Rivers, as well as the Great Divide Closed Basin. This geographic area was chosen primarily for two reasons: (1) it has tremendous resource values in terms of energy, habitat and wildlife, livestock grazing, and recreation; and (2) the pattern of land ownership includes large, contiguous blocks of public lands. The high value of natural resources combined with large areas of publicly managed lands provides unique opportunities for planning, resource use, and resource conservation across a large and diverse landscape affecting numerous public and private stakeholders.

\section{Ecosystems and Habitat Types}

\section{Sagebrush Steppe}

Sagebrush steppe, which dominates the semiarid intermountain basins of the Western United States, is characterized by sagebrush (Artemisia spp.), other shrub species, and native grasses. In southwest Wyoming, basin and Wyoming big sagebrush (A. tridentata Nutt. ssp. tridentata and $A$. tridentata Nutt. ssp. wyomingensis Beetle \& Young, respectively) are the dominant sage species, although five other sagebrush species also occur in the area, and significant amounts of mountain big sagebrush (A. tridentata Nutt. ssp. vaseyana (Rydb.) Beetle) occur at the higher elevations and in areas with greater moisture availability (Knight, 1994). In general, sagebrush ecosystems achieve maximum productivity in areas where most of the precipitation falls in the winter and where water becomes limiting in mid- to late summer.

Sagebrush provides significant habitat (food and shelter) for species such as mule deer, elk, pronghorn, and sage-grouse. Sagebrush shrubs may contribute to system productivity by trapping wind-blown organic material and snow on the lee sides of shrubs, thus enhancing conditions for both existing nearby shrubs and the establishment of additional shrubs. Historically, natural disturbances that led to ecosystem change in sagebrush steppe included fire and drought. More recently, disturbances also have included intensive livestock grazing (and accompanying chemical or mechanical treatments to remove sage), invasions of nonnative plant species (such as cheatgrass [Bromus tectorum]), and atypical fire behavior due to changes in plant community structure and composition (for example, throughout the sage-steppe biome, the presence of cheatgrass has altered fire regimes and intensities).

\section{Mixed-Foothill Shrubland}

Mixed-foothill shrubland refers to the vegetation that occurs in the transition zones between the sagebrush steppe and the higher-elevation mountains and escarpments at approximately 4,900-7,500 feet in elevation. In these locations it is cooler and wetter than it is in the sagebrush steppe, and mountain big sagebrush is the dominant sage species. Other shrubs in this habitat type include antelope bitterbrush (Purshia tridentata (Pursh) DC.), chokecherry (Prunus virginiana L.), serviceberry (Amelanchier alnifolia (Nutt.) Nutt. ex M. Roemer), skunkbush sumac (Rhus trilobata Nutt.), snowberry (Symphoricarpos spp.), snowbrush ceanothus (Ceanothus velutinus Dougl. ex Hook), and wild rose (Rosa spp.) (Knight, 1994). Other plant species commonly include the grasses and forbs that associate with sagebrush and foothill grasslands, such as bluebunch wheatgrass (Pseudoroegneria spicata (Pursh) A. Löve), junegrass (Koeleria macrantha (Ledeb.) J.A. Schultes), arrowleaf balsamroot (Balsamorhiza sagittata (Pursh) Nutt.), hairy goldenaster (Heterotheca villosa (Pursh) Shinners), and lupine (Lupinus spp.) (Knight, 1994). 


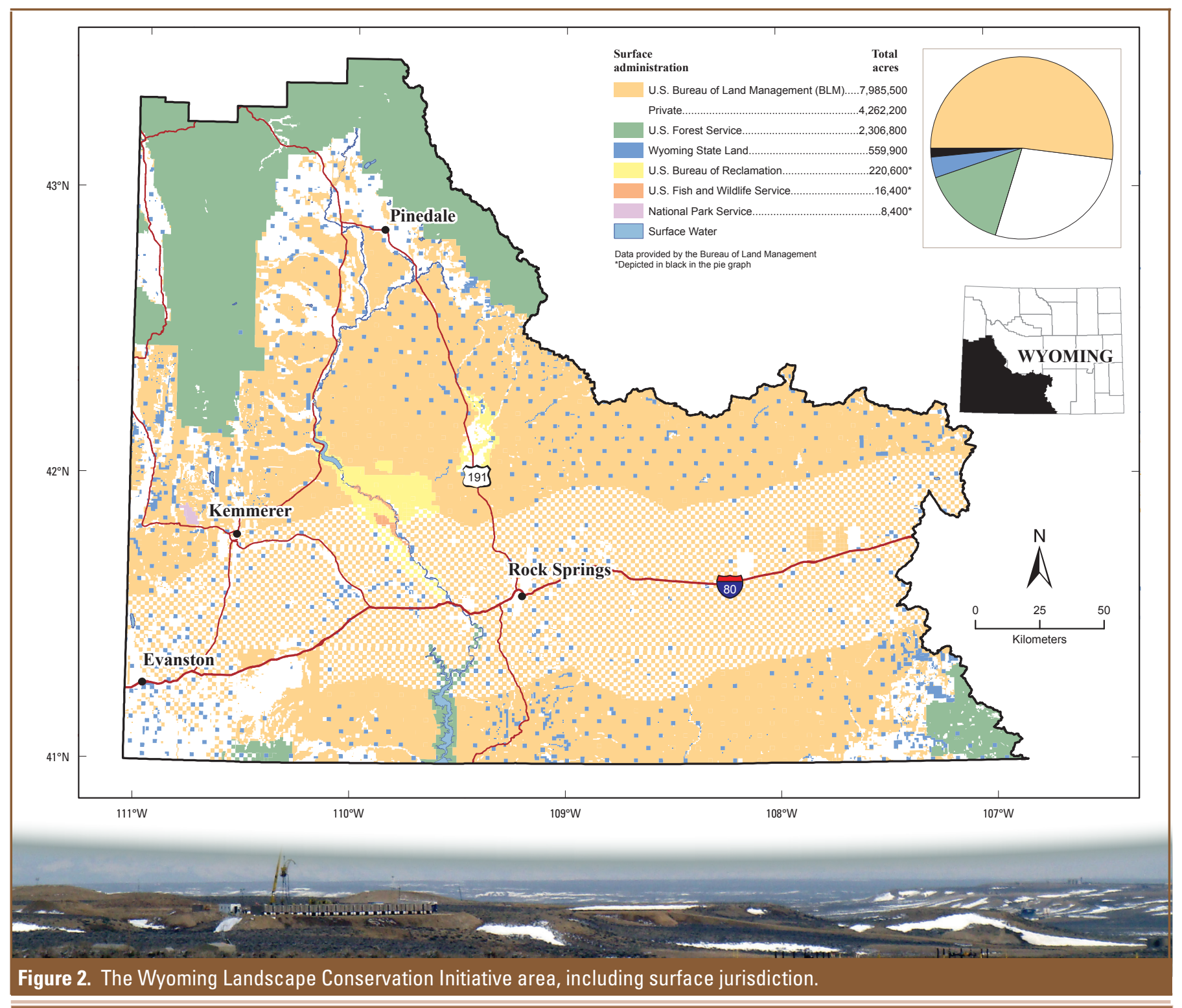

Knight (1994) pointed out the similarities of this type to riparian zones in terms of their contributions to plant species diversity and the crucial wildlife habitat-particularly winter habitat-that it provides.

\section{Aspen}

Aspen (Populus tremuloides Michx.) foothill woodlands, which differ from montane aspen forests, often occur in foothill riparian zones, moist ravines, and in snowdrift areas or seeps, which are wetter and cooler than surrounding foothill habitats. Understory vegetation can be similar to that of mountain meadows and aspen forests, and may include alpine bistort (Polygonum viviparum L.), shrubby cinquefoil (Pentaphylloides floribunda (Pursh) A. Löve nom. superfl.), and tufted hairgrass (Deschampsia caespitosa
(L.) Beauv.) (Knight, 1994). Aspen management has been controversial because the species is undergoing sharp decline in some regions (and a general declining trend across the landscape) that has been attributed to overbrowsing (aspen represent an important food source for ungulates in winter and spring) and fire suppression. Remedying these problems requires management changes likely to be unpopular with some affected publics. Aspen's clonal nature, its limited establishment from seed, and its palatability to cattle and wildlife are important characteristics that need consideration when managing aspen ecosystems. For example, although fire may be necessary to reduce conifer cover and allow aspen clones to regain dominance (which may last for 75-100 years), excessive browsing on aspen shoots may preclude aspen recruitment, maturation, and the characteristics that typify aspen ecosystems. 


\section{Riparian}

Riparian ecosystems are found along the margins of creeks and rivers. Lowland riparian areas in southwest Wyoming are characterized by willows (Salix spp.), sedges (Carex spp.), and other species adapted to wetlands, including narrowleaf (Populus angustifolia) and plains ( $P$. deltoides) cottonwoods in areas influenced by dependable streamflow and episodic flooding that together provide surfaces suitable for willow and cottonwood establishment (Knight, 1994). Although riparian zones represent 1 percent (or less) of the Wyoming landscape, approximately 80 percent of the native animals depend on them at some time during the year for water, food, and shelter, and many species use them as seasonal migration routes. Anthropogenic water use (for example, irrigation, livestock, industry, household) and developments that alter the quantity, quality, and timing of the hydrologic regime result in significant changes to associated riparian ecosystems.

\section{Aquatic}

In southwestern Wyoming, aquatic habitats are represented by rivers, streams, lakes, and ponds, including beaver ponds and off-channel pools along rivers and streams. The region encompasses headwaters for three of the Nation's major drainage systems: the Colorado and Columbia Rivers and the Bonneville Basin. The associated aquatic habitats are shaped primarily by topography and climate. Those occurring on valley floors, where elevations range from more than 5,000 feet to nearly 8,000 feet, are frequently ice-covered for 4-5 months of the year. The Green and Bear River Basins receive only 10-15 inches of precipitation annually, the majority occurring as snowfall, whereas the Wyoming and Salt River Ranges and the Uinta and Wind River Mountains receive significantly greater amounts of annual precipitation. At lower elevations, snowmelt contributes the majority of water to these systems; thus, aquatic habitat types on valley floors are generally confined to the main river channels and nearby off-channel areas. In mountainous areas, however, lakes, ponds, and streams are more common, reflecting the relative abundance of water provided by snowmelt in those areas. In the Wyoming and Salt River Ranges, streams are held in wide, willow-covered valley floors characterized by highly sinuous channels and deeply undercut banks. The major drainages of southwest Wyoming support 17 native fish species, 12 of which the CWCS identifies as Species of Greatest Conservation Need (Wyoming Game and Fish Department, 2005; see http://gf.state.wy.us/wildlife/CompConvStrategy/ SectionI.pdf).

\section{Ecosystem Dynamics}

\section{Natural Change}

Ecosystems are dynamic entities that vary across time and space in response to a variety of natural processes (such as climate). Change is an important component of ecosystems, resulting from interactions between disturbance (such as fire) and subsequent successional processes. The paleoenvironmental record illustrates the magnitude and variability of past ecosystem changes, such as the expansion and contraction of species ranges on timescales ranging from centuries to millennia (Davis and Shaw, 2001). Understanding the past, present, and future dynamics of ecosystems in the WLCI study area and how changes resulting from recent/ current land use differ from those generated by previous patterns of disturbance and succession is a fundamental component of the Strategy that will be addressed and repeatedly refined through retrospective studies, modeling future scenarios, and conducting long-term monitoring.

\section{Anthropogenic Change}

The natural dynamics of ecosystems have been modified by human activities - more so as human populations have grown and technologies have advanced (Turner and others, 1990). Human activities, including land uses such as agriculture, directly modify ecosystems. Other anthropogenic changes, such as fire suppression, indirectly alter ecosystems by changing disturbance regimes. Ecosystems of the WLCI study area have been influenced by many anthropogenic activities, including development of energy and housing, livestock grazing, recreation, and other land uses. Improving the understanding of how these activities, including their human dimensions components, affect ecosystem function is necessary for successful conservation and management of WLCI ecosystems.

\section{The Interactive Effects of Natural and Anthropogenic Changes}

The interactions between natural ecosystem dynamics and human activities can have large impacts on ecosystems; thus, it is crucial to consider these effects when planning and developing research and conservation activities. In addition to direct effects (for example, land-use conversion), indirect effects of human activities also may amplify natural environmental changes and accelerate rates of change beyond those that ecosystems have undergone in the recent past. Understanding the combined effects of natural and anthropogenic changes, including the socioeconomics that drive anthropogenic change, is important to land managers, 
particularly since these factors could influence the suitability of management activities. For example, NPS managers have tried to identify and re-create fire regimes of pre-European settlement eras in national parks; however, it may not be possible to reestablish historical fire regimes because of potential interactive effects of climate change (anthropogenic or natural), changes to vegetation communities (for example, invasion of cheatgrass), and human land uses that are incompatible with fire, such as developments of housing and energy infrastructure.

\section{WLCI Management Needs for} Evaluating Cumulative Environmental Effects of Development Activities in Southwest Wyoming

By definition, cumulative effects are those that accumulate over time because of multiple independent decisions and development actions that affect - positively and(or) negatively - the physical, biotic, and human environments in a given geographic region of interest (Orians and others, 2003). If the cumulative effects of all decisions affecting a given ecosystem are not considered or understood, then the true patterns of change over large areas and long periods cannot be factored into the decisionmaking process. Therefore, the focus of the six management needs identified by WLCI partners and collaborators - and the overall goal of USGS WLCI science-is to evaluate, monitor, and assess the cumulative effects of development activities and identify drivers of change on terrestrial and aquatic habitats and wildlife populations in southwest Wyoming.

During the past several decades, there has been extensive research to address various effects of oil and gas exploration activities on wildlife populations and their habitats in areas that overlap the WLCI study area. Some of these efforts have focused on individual species, such as sage-grouse (Holloran, 2005), mule deer (Sawyer and others, 2002), and pronghorn (Berger, 2004). Other studies have entailed an ecosystem approach, including the development of landscape-scale conservation plans (Freilich and others, 2001; Neely and others, 2001; Noss and others, 2001), conducting ecoregional assessments for addressing anthropogenic footprints, and evaluating habitat needs for multiple species of conservation concern (Rowland and others, 2006). Both previous and ongoing work within the WLCI study area will be used to help address the WLCI management needs and assess the cumulative effects of development and other activities. Whereas none of the previous studies within the WLCI study area have taken a landscape-scale approach to address all the cumulative effects of anthropogenic activities in that region, the WBEA (Rowland and others, 2006), which overlaps the entire WLCI area, represents the most comprehensive analysis to date. The WBEA, therefore, will serve as a foundation for developing a comprehensive and interdisciplinary assessment of cumulative effects across the diverse and complex WLCI region.

In this section, each of the six management needs identified for the WLCI is briefly described then followed by a list of objectives for addressing that management need; also provided are lists of priority short-term (immediate) and longterm (several years) research and technical assistance activities for meeting the objectives. Components of the research priorities will be integral to the larger cumulative effects assessment for southwest Wyoming. As science begins to address research questions implicit in the management needs and objectives, it will simultaneously build the foundation for assessing known and probable cumulative impacts of anthropogenic activities and identify the drivers of change affecting aquatic and terrestrial wildlife species and their habitats.

\section{Identify Key Drivers of Change}

There are numerous driving forces that directly and indirectly cause ecosystem change, such as energy and urban development, climate change, fire, invasive species, and livestock grazing. The WLCI impetus is concern about the potential effects of energy development on terrestrial and aquatic wildlife and habitats in southwest Wyoming. Although there is little information on the actual effects of energy development - predominantly the extraction of natural gas - visible changes to the landscape are obvious and ongoing. Indeed, energy development is repeatedly identified in the WLCI Concept Paper (Interagency Wyoming Landscape Conservation Initiative Planning Group, 2006), planning documents from the U.S. Department of the Interior (DOI), WLCI informational materials, and in various USGS and stakeholder meetings and workshops as a key driver of change in the southwest Wyoming region.

Climate also has been identified repeatedly as a key driver of change in the WLCI region. For example, drought conditions since 2000 - as measured by streamflowgaging stations - have been among the most severe, in both duration and magnitude, recorded since the early 1900s. Streamflow and precipitation records constructed as proxies for paleoclimates of the Upper Colorado River Basin indicate that droughts of even greater frequency, duration, and magnitude occurred prior to those measured by instruments and documented in the records. Both short- and long-term climate variability can change WLCI ecosystems directly, as may the interactive effects of climate change and other drivers of change. For example, the combined effects of drought and grazing could be far more pronounced than those of either driver alone; thus, drought is a consideration when establishing stocking rates for livestock grazing which, in turn, 
affects ranching operations. Similarly, drought may affect the size of areas required for conservation efforts.

The Science Team will identify key drivers of change affecting WLCI ecosystems, describe the changes (including their spatial and temporal occurrences), and qualify their relative significance in terms of the urgency for addressing and the potential for reversing them. In preparation, the Science Team has compiled a working list of potentially important drivers of change (in alphabetical order).

- Agricultural practices

Livestock grazing

Irrigation

- Air quality

- Climate variability

- Disease

- Energy development

Biomass

Coal

Natural gas

Oil

Oil shale

Uranium

Wind

- Fire

Natural

Prescribed

- Infrastructure development

- Invasive species

- Policy (public land management)

Interpretation of multiple-use mandates

Prescribed fire

Seeding and other vegetation treatments

Land conservation and preservation actions

- Recreation (including off-road vehicles)

- Sprawl (urban/suburban development)

- Vehicles (traffic)

- Water use

Diversion

Extraction

Storage

Initial science efforts will focus on the two key drivers of change cited most often: energy development and climate variability. Historical data on energy leasing, exploration, and drilling, as well as mining, will be compiled, and maps characterizing the distribution and pace of development will be generated annually (or more frequently). In addition, paleoclimate proxies will be refined or developed for the
WLCI area, and maps characterizing basin-scale climate variability will be generated. Available plant and animal occurrence and distribution data will be compiled from multiple sources to provide a perspective of changes to date in the context of the energy development and climate variability time series. In addition to providing resource managers with a historical framework leading up to current landscape conditions, these initial efforts will provide the foundation for predictive modeling of future landscapes based on various energy-development scenarios, other land uses, and climate change. Efforts also will include prioritizing and characterizing other potential drivers of change and addressing spatial and temporal data needs identified by the initial efforts.

\section{Objectives for Addressing Management Need 1}

- Identify, quantify, and prioritize key drivers of change in southwest Wyoming ecosystems, including multiple drivers that interact and historically were measured inadequately (for example, energy footprints over time-including initial surficial disturbance and associated short- and long-term disturbances, fire, invasive species, and livestock grazing).

- Develop new methods or improve/refine models for predicting potential changes in key drivers over time and projecting probable future responses to those changes.

- Improve the predictive capabilities of future scenario models and update scientific understanding of the origin and occurrence of energy and mineral resources based on the most current information on viable deposit types and assessments units.

- Develop methods to assess the full costs (including exploration, extraction, and use) of energy and mineral development.

\section{Short-Term Activities for Meeting Objectives}

- Obtain and compile all available information on historical energy leasing, exploration, and drilling, as well as mining, on at least an annual basis.

- Obtain and compile historical climate data and projected drought conditions for southwest Wyoming.

- Develop time-series maps of energy development and climate to quantify changes and analyze patterns from 1900 to 1950 .

- Combine models of key drivers and other stressors with habitat and species data (see activities under Management Need 2) to examine relations between drivers and biological responses over time. 
- Obtain and begin compiling available information on socioeconomic drivers of ecosystem change in southwest Wyoming.

\section{Long-Term Activities for Meeting Objectives}

- Refine estimates for energy-resource maps that depict development "hotspots."

- Use historical data, improved petroleum-resource maps, leasing information, and other ancillary data, and engage industry experts to improve the resolution (grain) of this information for generating future energy-development scenarios.

- Develop a logical method for model averaging or model refinement to allow down-scaling of models for more precise prediction of climate change in southwest Wyoming.

- Use the improved models of energy development and climate change to improve predictions of habitat and species responses.

- Expand analyses of energy development and climate change to generate full ecosystem and economic cost estimates for different development scenarios.

- Conduct analyses to quantify the socioeconomic drivers of ecosystem change, then build these drivers into the models for assessing biological responses to key drivers of change.

- Develop cost:benefit analyses of energy and mineral exploration and development in terms of socioeconomics and loss or gain of ecosystem goods and services.

\section{Identify Condition and Distribution of Key Wildlife Species, Habitats, and Species Habitat Requirements}

Sagebrush steppe, mixed-foothill shrubland, aspen, riparian, and aquatic community types in southwest Wyoming are among the most intact native ecosystems remaining in the Intermountain West. Each provides valuable and unique habitats; however, increasing development and landscapelevel changes are threatening many of these already impacted systems and the species they support. Rigorous science designed to identify and delineate key habitats for wildlife species, especially species with special status, is required for making informed management decisions, including where to conduct restoration and enhancement projects. In addition, results of scientific studies will provide the foundation for developing BMPs to address potential consequences of existing and landscape-level changes. Before science can address important management needs for wildlife and habitats, however, key data gaps, baseline conditions, and several broad research objectives need to be addressed (summarized in the next section). Conducting the short-term science activities will help guide on-the-ground management, making these activities a priority. Many of these activities will overlap with those conducted for other management needs, and all will assist with the overall WLCI science goal of evaluating the cumulative environmental effects of development activities.

\section{Objectives for Addressing Management Need 2}

- Identify key aquatic and terrestrial species (including indicator, umbrella, socially and economically important species, and species with special status) or groupings of species.

- Assess baseline conditions and determine landscapelevel habitat requirements for important aquatic and terrestrial species (defined as those with special status, keystone species, and(or) those considered economically and socially important).

- Using the Wyoming Game and Fish Department's (WGFD) Strategic Habitat Plan and CWCS (Wyoming Game and Fish Department, 2005) as a foundation, delineate spatial and temporal distribution of habitats, mapping key and high-quality habitats for key species or groups of species.

- Identify key areas of conservation concern/priority by mapping important, sensitive, and rare habitats, as well as critical habitats required for the long-term persistence of one or more key wildlife species (these could include important nesting, rearing, wintering, spawning, or migration habitats). This activity will require a thorough understanding of how resources and drivers of change (for example, climate, energy development, urban expansion, livestock grazing) affect both the occurrence (where animals go) and fitness (survival and reproduction) of wildlife.

- Identify the vulnerability and sensitivity of key habitats/areas to the key drivers of change. This activity will require a spatial understanding of where developments/disturbances currently occur, assessing wildlife and habitat responses to key drivers associated with development and disturbance, and understanding — spatially and temporally—how and where future developments will occur, and their potential impact on wildlife and habitats. 
- Relate habitat characteristics to animal distribution and population dynamics (for example, some index of habitat quality for a given species) to assess the effects of key drivers of change on aquatic and terrestrial wildlife and habitats.

\section{Short-Term Activities for Meeting Objectives}

- Identify data gaps regarding key species, including life history, spatial and temporal distribution, and population status.

- Gather empirical data for key species of concern (see WBEA [Rowland and others, 2006] and the Wyoming Natural Heritage Program's Natural Diversity Database at http://uwadmnweb.uwyo.edu/wyndd/).

- Gather detailed spatial data on infrastructure (see Wyoming Oil and Gas Conservation Commission data at http://wogcc.state.wy.us/, and USGS infrastructure mapping project for southwest Wyoming at http:// sagemap.wr.usgs.gov/).

- Gather spatial habitat-data layers, including new spatial habitat maps (see USGS SAGEBRUSH at http:// sagemap.wr.usgs.gov/ and "Multiscale sagebrush range land habitat modeling in southwest Wyoming at http://pubs.usgs.gov/of/2008/1027, LANDFIRE products at http://www.landfire.gov/products_overview. php, and Wyoming Geographic Information Science Center at http://www.wygisc.uwyo.edu/data.htm) to be used in (1) mapping key habitats, and (2) developing spatial models that depict key resources/areas for wildlife species of concern (see WBEA [Rowland and others, 2006] and Marxan conservation planning software - a tool for identifying sites/areas that meet a broad range of conservation criteria [http:// www.uq.edu.au/marxan/]; see an example of how this software has been used in Kiesecker and others [2009]; also see http://www.wy.blm.gov/jonah_officel newsletter/2007/08e.htm). This activity will provide information for managers regarding where key conservation/preservation areas should be placed, as well as assist with identifying key areas for mitigation.

- Map bedrock, surficial deposits, and soils in priority areas to aid in determining baseline conditions for the various habitats.

- Determine the landscape geochemistry (soil geochemistry) of undisturbed priority and disturbed areas to aid in determining baseline conditions, the effects of development, and implications to mitigation and restoration.

\section{Long-Term Activities for Meeting Objectives}

- Identify key areas of future energy development (see BLM and USGS mapping efforts at http://sagemap. wr.usgs.gov/).

- Spatially map livestock grazing across the landscape: allotments, animal unit months (AUMs; permitted and billed), BLM's Land Health Standards, and so on (see USGS-BLM Grazing Project at http://www.fort.usgs. gov/Research/research_tasks.asp?TaskID=2320).

- Assess effects of climate change on habitats across the landscape (see USGS EFFECTS Project at http:// esp.cr.usgs.gov/infoleffects/ and USGS Global Change Science at http://www.usgs.gov/global_change/). (See activities for Management Need 1.)

- Develop plausible future-scenario maps within the sites identified as key habitats and resource areas for wildlife species of concern or surface development, livestock grazing, and climate change.

- Apply current spatial wildlife models described in the WBEA (Rowland and others, 2006) to future landscapes, and assess the effects of various scenarios on key wildlife species of concern.

- Using WGFD's CWCS (Wyoming Game and Fish Department, 2005) as a foundation, develop data collection strategies relevant to key species for which data are insufficient to develop complete assessments.

- Refine models identifying key resources/areas as new spatial data layers (wildlife, habitats) become available.

- Establish long-term monitoring of mitigation treatments and wildlife species potentially affected by current and future developments (see activities for Management Need 5).

- Apply the principles of adaptive management to allow for successful implementation of conservation science.

\section{Evaluate Wildlife and Livestock Responses to Development}

Much research has been conducted on the impacts to aquatic and terrestrial wildlife species caused by development, particularly the direct influence of habitat loss. In southwest Wyoming, some species, such as sage-grouse, mule deer, and cutthroat trout, have been well studied, and for these species we are beginning to understand the effects of energy development, the spatial and temporal scale at which these effects are manifested, and some of the mechanisms that lead to these effects. Relatively little is known, however, about the influence of energy development on most of southwest 
Wyoming's aquatic and terrestrial habitats and wildlife populations, including both socially and economically important species, and the vast majority of Wyoming's SGCN. There are similar concerns regarding the effects of energy development on livestock grazing systems. In addition to habitat conversion, energy development generates excessive dust levels, alters hydrology in such a way that forage production may be diminished, and inhibits rancher abilities to manage livestock appropriately. Although dust and altered hydrology have been identified as potential effects of energy development, they have yet to be quantified and evaluated.

Research conducted for this management need will focus on the effects of energy development, climate change, and other drivers identified as affecting wildlife and livestock and will entail process or mechanism studies that typically require multiple years to complete. Efforts will involve assessing both individual (for example, physiology, stress responses) and population (such as demographics) responses of wildlife and livestock to development. Additional work will entail measuring population and stock performance across habitats and disturbance levels and will help identify suites of wildlife habitat or livestock-rangeland conditions most likely to provide conservation value.

\section{Objectives for Addressing Management Need 3}

- Evaluate the direct effects of energy development and other major drivers on the physiology and demographic performance of wildlife (both individual species and species groups) and livestock.

- Evaluate indirect effects of habitat alteration on wildlife and livestock that are due to invasions of nonnative plants, changes in disturbance regimes, increased susceptibility to disease, altered social dynamics, or other changes.

- Assess the different patch-size needs and edge effects that influence the behavior, population structure, and population growth of wildlife.

- Develop methods for assessing the influence of energy development on livestock-management systems.

\section{Short-Term Activities for Meeting Objectives}

- Identify, collect, and synthesize existing information for species of concern as a foundation for individual and population studies (see activities proposed for Management Need 2).

- Initiate research addressing individual- and populationlevel effects on important wildlife species of concern.
- Identify priority areas for key life stages of livestock, including lambing and calving, trailing, and wintering areas.

- Identify priority areas for key life stages of wildlife, including production and rearing of young, migration corridors, and crucial seasonal ranges (see activities proposed for Management Need 2).

- Determine the availability and content of livestockproduction data for southwest Wyoming.

- Collect information on livestock grazing leases, including allotted use and actual use.

\section{Long-Term Activities for Meeting Objectives}

- Evaluate both demographic and population-level responses to development and develop models that can project population growth and viability under different levels of energy development and management scenarios.

- Identify connections between habitat configuration (broadly defined) and commensurate wildlife response in terms of behavior, physiology, migration/movement, demography, and population numbers.

- Identify areas of high conservation value.

- Identify the species that are most vulnerable to development and for which WLCI partners and managers have the greatest information need.

- Assess the relationship between levels of energy development and quality and availability of forage.

- Evaluate the physiological costs of increased stress generated by development on wildlife and livestock.

- Develop methods for evaluating the influence of energy development on livestock management systems.

\section{Evaluate the Effectiveness of Restoration, Reclamation, and Mitigation Activities}

The BLM is cooperating with other partners and collaborators to evaluate, develop, and implement large-scale, focused habitat protection and restoration projects on BLMmanaged lands and adjoining State and private lands that are not directly affected by energy development. Additional habitat-improvement projects include those on private lands funded by the FWS Partners for Fish and Wildlife Program, as well as projects on lands administered by the USFS. Project types might include planting or seeding; fencing important 
wetlands, altering fence heights/types, or removing fencing; or developing conservation easements. Common objectives for these projects include addressing habitat fragmentation, assessing the quality and suitability of native vegetation to support fish and wildlife species, documenting the occurrence of invasive plant species, and protecting high-quality habitat. Improving wildlife habitat will promote its sustainability, improve the potential for species recoveries, and help preclude many species from becoming jeopardized.

Monitoring and research are needed to serve as the basis for selecting, implementing, and refining or improving the effectiveness of restoration, reclamation, and mitigation actions. The Science Team will focus on monitoring and research studies designed to evaluate the effectiveness of these activities, document species responses to treatments, and assess the performance of implemented reclamation approaches. In turn, these results will be used to assist WLCI partners in developing and guiding improvement and restoration projects, ensuring that projects are implemented in the most appropriate locations, improving and adapting reclamation strategies, and facilitating the development, incorporation, and refinement of BMPs.

Monitoring the performance of restoration and habitatimprovement projects and reclamation efforts is essential to determine the success of implemented treatments and improve on BMPs. Monitoring alone, however, does not identify the primary drivers responsible for the observed responses. Carefully designed research studies must be implemented to determine the relationships between observed resource responses and management treatments. When appropriate, hypothesis-based, comparative monitoring strategies will be designed based on the three-phase approach described in the Research and Monitoring Approaches section. Observational monitoring in conjunction with hypothesis-based experimental research will support quantitative biotic and abiotic assessments of completed treatments and contribute to adaptive management. Information and data derived from new and extant sources combined with planned synthesis activities (also described in the Research and Monitoring Approaches section) will be used to maximize the utility and relevance of experimental designs and the interpretability of their results.

The Science Team will collaborate with WLCI members and other resource managers to identify critical information needs and collect information about recent and current projects. In addition, the Science Team will develop appropriate sampling designs, assess response variables, and interpret findings as feedback to help guide adaptive management and help optimize reclamation, restoration, and wildlife conservation projects.

\section{Objectives for Addressing Management Need 4}

- Evaluate the effectiveness of specific habitatimprovement and restoration practices in different habitat types and precipitation zones.
- Evaluate and guide the refinement of BMPs.

- Evaluate the relationships between observed resource responses and management activities, including restoration, reclamation, and habitat-improvement projects.

- Design a framework for objectively developing the most effective restoration and enhancement projects on a landscape scale.

\section{Short-Term Activities for Meeting Objectives}

- Collect and review available information on wildlife and habitat conservation, restoration, and reclamation projects from WLCI partners (BLM, WGFD, JIO), industry operators, and others (Wyoming Wildlife Trust).

- Incorporate locations of wildlife and habitat conservation, restoration, and reclamation projects into a Web-based mapping application.

- Identify (FY 2007 and 2008) projects that lack adequate pretreatment and posttreatment assessments.

- Evaluate and prioritize suitable projects for application of pretreatment and posttreatment assessments.

- Document the responses of key plant and wildlife species to reclamation approaches.

- Document the geochemical response of soils to disturbance and reclamation.

\section{Long-Term Activities for Meeting Objectives}

- Develop a framework for annual evaluations of all proposed wildlife habitat-improvement projects, and, in collaboration with the resource-management agencies, use these evaluations to develop priorities for subsequent actions.

- Design and implement monitoring protocols for tracking changes to aquatic and terrestrial biota associated with reclamation, restoration, and wildlife conservation projects.

- Collect information on species and habitats, and assess current habitat-suitability indices, to quantify the effects of alternative management plans and land treatments over time.

- Develop models capable of integrating data across various spatial and temporal scales to answer key questions about reclamation, restoration, and wildlife conservation projects. 
- Design comparative experiments to evaluate the relative effectiveness of reclamation, restoration, and wildlife conservation projects and assess their contribution toward the sustainability of important species and habitats.

\section{Develop an Integrated Inventory and Monitoring Strategy}

Inventory and monitoring (I\&M) is an essential tool for understanding the status and trends of plant and animal populations and ecosystem health and for evaluating the effectiveness of management actions and conservation projects. The Science Team is committed to conducting inventories of species and habitats, monitoring natural resources and species, synthesizing habitat and energy information, and building on existing and ongoing studies. For the WLCI study area, the USGS will develop I\&M strategies that efficiently and effectively measure the aquatic and terrestrial conditions that will aid resource managers in their decisionmaking. If at some point any given land-management agency adopts standard protocols for monitoring, they will be taken into consideration. USGS I\&M activities will focus on (1) cumulative effects and ecosystem monitoring, (2) project monitoring, and (3) adaptive monitoring/early warning.

Assessing cumulative effects and monitoring ecosystems entails long-term, large-area monitoring designed to address complex processes over large spatial scales. Oil and gas development may be the most rapidly evolving land-use activity in the WLCI region; thus, mapping and monitoring the evolution of that development and its impacts is a priority. Also fundamental to monitoring trends among species of concern or other natural resources is understanding how agriculture, drought, water development and use, urban and exurban expansion, energy development and its infrastructure, and other human activities are affecting natural resources at landscape and regional scales. For example, energy development, agricultural use, water development, and climate variability (drought) may affect water quantity/quality and the timing of streamflow in streams miles away from the land-use activities in question. The cumulative effects of several types of land-use activities may have substantial impacts on land cover, wildlife habitats, water resources, and other factors.

A primary objective of the WLCI is to minimize effects of development and other land-use activities on terrestrial and aquatic wildlife and important habitats. To meet this challenge, WLCI partners and collaborators will implement on-the-ground projects designed to restore, enhance, protect, and conserve habitats used by sensitive or important species. Whereas these habitat projects will be conducted in all habitat types, the WLCI focus is on sagebrush, mountain shrub, aspen, and riparian communities. Habitat-improvement projects also may focus on areas where other habitat improvements are taking place (such as those conducted by WGFD and Wyoming Wildlife and Natural Resource Trust) but, for obvious reasons, they will not be conducted where major future developments (such as housing and other permanent developments) are expected (reclamation of recoverable industrial sites is to be conducted by industry). USGS scientists will work with DOI, WLCI partners, the WLCI STAC, and the WLCI monitoring subcommittee to monitor the effectiveness of these habitat improvements. Monitoring habitat projects in conjunction with baseline and cumulative-effects monitoring will help focus and prioritize where and how to implement future habitat projects.

Monitoring protocols are implemented to measure specific conditions or processes. Given future uncertainties, however, managers and monitoring protocols must be adaptable. Examples of uncertainties include extreme weather events - such as droughts, floods, or unseasonable temperatures - and atypical fire events, disease outbreaks, or introductions/range expansions of invasive species. Monitoring protocols also must be flexible enough to adapt to changes in socioeconomic drivers. Examples include changes in the price of fossil fuels that can influence the rate of energy exploration and development or changes in technology that allow exploitation of reserves or alternative resources (such as oil shale) that previously were not economically feasible to exploit. Appropriate monitoring may enable detection of subtle changes in conditions or processes that otherwise would not be detected. These subtle changes can serve as an early warning, allowing resource managers to make changes to their resource management plans.

\section{Objectives for Addressing Management Need 5}

- Develop an inventory and monitoring approach designed to evaluate the overall effectiveness of the WLCI, including the effectiveness of habitat improvement and restoration projects, and support the analysis of cumulative effects.

- Coordinate with WLCI partners to help establish monitoring strategies and protocols to be implemented at a landscape scale.

- Integrate inventory and monitoring programs developed for the WLCI with other local, State, and Federal efforts.

- Make inventory and monitoring information accessible to WLCI partners and resource managers through a data-management framework and data clearinghouse.

- Integrate inventory and monitoring efforts into an adaptive management framework. 


\section{Short-Term Activities for Meeting Objectives}

- In the WLCI study area, continue to operate existing USGS monitoring networks (water quantity and quality, terrestrial habitats and species) that employ existing, published, and well-accepted protocols and methods.

- Continue current USGS interdisciplinary remotesensing and mapping applications, such as the inventory of sagebrush communities throughout Wyoming; the mapping of sagebrush species and measuring of their abundance and structure; and developing baseline predictive models applicable across the project area. Begin to build species and habitat models for future assessments.

- Develop strategies and protocols for long-term monitoring of priority species and habitats, including sensitive and sage-obligate species.

- Review existing Federal, State, and other organizational monitoring programs (drought, climate) at local, regional, and national scales and integrate and synthesize past and current biologic, geologic, geographic, and hydrologic data to identify information gaps and to prioritize short-term and longterm management needs.

- Collect and review available information on wildlife and conservation projects from WLCI partners (BLM, WGFD, JIO), industry operators, and others (Wyoming Wildlife Trust). Evaluate data gaps and prioritize treatments conducted during 2008 and 2009.

- Inventory information on land status, land use, land cover, vegetation, wildlife species, livestock-grazing management practices and associated allotments, anthropogenic disturbances, and landscape or ecosystem features not currently being inventoried by USGS and WLCI partners. This activity will be accomplished by collecting information from WLCI partners and collaborators (The Nature Conservancy, Wyoming Wildlife Trust, Wyoming Natural Diversity Database) and with tools such as remote sensing and modeling.

- Incorporate current inventory and monitoring information from WLCI partners and collaborators into the WLCI data/information-management system and clearinghouse.

\section{Long-Term Activities for Meeting Objectives}

- Evaluate the adequacy and robustness of existing monitoring and inventory protocols.
- Develop and implement consistent protocols across agencies, jurisdictions, and ownerships.

- Design and implement a basin-wide monitoring network for water quantity and quality and air quality.

- Conduct long-term monitoring of land use, land cover, vegetation, energy development, and socioeconomic drivers of change.

- Design and implement monitoring to understand current conditions for specified species and habitats, and identify and track changes to aquatic and terrestrial biota and habitats by using existing, published, and valid protocols and methods.

- Design and implement monitoring of priority species and habitats for status and trends related to human disturbance and restoration activities.

\section{Develop a Data Clearinghouse and Information-Management Framework}

In cooperation with other WLCI partners, especially those providing relevant information, USGS scientists will build the geospatial and project-management framework for accessing and sharing information between Science Team members and other partners. Partners will retain ownership, and in most cases maintenance responsibility, of their respective information; USGS will provide centralized data hosting and linking to partner databases, GIS and datavisualization support, and project-management services. USGS also will ensure compliance with the Federal Geographic Data Committee (FGDC) metadata standards, including maintaining security of confidential, sensitive, or proprietary information. Where feasible, work will be accomplished by leveraging existing professional services, expertise, and resources. The result of this effort will be a sustainable resource of scientific information, knowledge, and tools to ensure that future decisions regarding land and natural-resource use, management practices, and energy development are based on a solid understanding of how biologic, geologic, hydrologic, and geographic processes relate to changes on the landscape.

\section{Objectives for Addressing Management Need 6}

- Develop an integrated, Web-based WLCI information clearinghouse with the capability to protect confidential, sensitive, and(or) proprietary information (http://my.usgs.gov/websites/wlci_revised/ dataclearinghouse.html).

- Develop and implement a project tracking and database system to provide summary reports on habitatimprovement projects that include spatial data display 
mechanisms (maps, spatial queries) and spatially filtered reports.

- Provide data-management, visualization, and decisionsupport tools for the WLCI.

- Provide public information and outreach on WLCI habitat improvement and science activities.

\section{Short-Term Activities for Meeting Objectives}

- Identify the existing state of knowledge applicable to this effort.

- Develop basic data-hosting capability and prioritization tools, and identify data gaps.

- Produce general reference map for educational overview purposes.

- Organize protocols for assembling data into the WLCI clearinghouse from different monitoring sources.

- Develop a spatially explicit project tracking tool (investigate existing efforts).

- Provide user-friendly education and outreach Web site.

\section{Long-Term Activities for Meeting Objectives}

- Assess costs for future upkeep of this development as a sustainable resource.

- Evolve basic data-hosting capability into more a permanent data serving and archiving system.

- Facilitate information contributions of partners by developing a suitable business model.

- Maintain a dynamic information site for partner and public access into the foreseeable future.

\section{Research and Monitoring Approaches}

\section{Range of Approaches Proposed for WLCI Science}

There are a number of common research approaches used for studying ecosystems. The approaches described below represent the spectrum of those proposed for the WLCI research program.
Retrospective Studies_-Retrospective studies are commonly used to reconstruct past ecosystem conditions and for understanding ecosystem variability over time. They range in temporal scale from paleoenvironmental studies of climate and ecosystem changes over millennia to studies that examine changes over recent time periods (Russell, 1997). Retrospective studies are also important for identifying ecosystem trends, and they can be used to evaluate responses of organisms to past land-management practices.

\section{Treatment and Control Studies_-These} approaches entail experiments in which similar units are subjected to different levels of treatment in an attempt to isolate the response relative to untreated units. These studies are most typically employed in agricultural research, as they are difficult to implement across large study areas like southwest Wyoming due to the difficulty of finding replicate landscapes and applying treatments across large areas. When feasible, however, experimental approaches can produce definitive and highly credible results.

Monitoring-Monitoring ecosystems is critical for documenting current conditions and identifying the magnitude and rate of subsequent changes, such as those driven by climate change. Monitoring also provides baseline data for evaluating the performance of models that describe ecosystem function, and it is a critical component of adaptive management, whereby the response to a land-use action guides future management. Monitoring techniques range from on-theground measurements to remote sensing.

Process Studies - In attempts to understand ecosystem function, researchers often find that ecological processes are poorly understood. Empirical, experimentally based studies are fundamental to understanding how systems function and respond to specific conditions. The processes to be studied may be based on knowledge gaps identified as part of a conceptual model analysis or model-based simulation of ecosystem dynamics.

Modeling-Models are useful tools for investigating ecosystem responses to a range of conditions. They range from qualitative conceptual models to complex quantitative models of ecosystem function, species-habitat relationships, and population viability. Models often are used to test hypotheses for which empirical studies cannot easily be carried out. They are particularly useful for simulating conditions over large areas or long time frames for which empirical data are not available. Models are also important for extrapolating ecosystem responses to future changes, such as forecasting the potential impacts of future climate change. 
Conceptual models are qualitative models used to describe a system - its component parts and processes. They can take many forms, including network and system diagrams, which identify the key components and processes of a system by using combinations of boxes and arrows. Such models can be used to identify possible cause-and-effect relationships, whereby changes to one part of the system affect another part of the system, and they are commonly used in cumulativeeffects analyses. Conceptual models are particularly useful for facilitating interdisciplinary communication about how a given system is believed to function (Heemskerk and others, 2003) and for identifying important knowledge gaps that can help guide future research. New conceptual models that will be developed to describe WLCI ecosystems will promote these and other basic understandings among scientists and resource managers involved in WLCI-based research.

\section{Optimizing Adaptive Management Through a Coordinated Research and Monitoring Program}

Establishing coordinated research coupled with an effective monitoring program can be challenging. Well-defined research and monitoring objectives often are unavailable, information is incomplete or inaccessible, and(or) new information is not used in evaluations of decisions and management actions; moreover, research on landscapes is complicated by the lack of control over numerous variables that can influence results at different spatial and temporal scales. Frequently, research and monitoring are not clearly linked to management and policies, resulting in research being conducted without any application to land management and(or) with poor definition of targets and thresholds. Involvement of multiple agencies often further confounds these issues; therefore, developing an effective and efficient monitoring approach and integrating it directly with adaptive management actions is a high priority in southwest Wyoming as it will help to ensure compliance with required regulations and coordination among multiple agencies. In addition, the emphasis on landscape-scale syntheses of new and existing information to address multiscale ecological and management questions demands a well-coordinated effort to ensure the overall success of the WLCI program.

Nichols and Williams (2006) described the key components of successful adaptive management and its relevance to monitoring. Adaptive management is a sequential decisionmaking process that is especially useful when there is a high degree of uncertainty about the outcome of management actions. Management decisions are informed through a process that includes developing management objectives, identifying potential management actions, developing or adapting models of system response to such actions, measuring confidence in the models, and using monitoring data and models that provide estimates of system states. At each decision point, alternative management actions are evaluated for specific management objectives; the appropriate action is based on estimates constantly updated by the latest knowledge of system responses and the system's predicted responses to management actions. Once the management action is implemented, monitoring is used to test the model's predictions. This approach is iterative and implemented at each subsequent decision point based on new estimates of system states and updated models (fig. 3).

Because it is USGS that will be conducting most of the science, but it is principally the participant land management agencies that will have to take both the ecological and human dimensions aspects into consideration and make the necessary

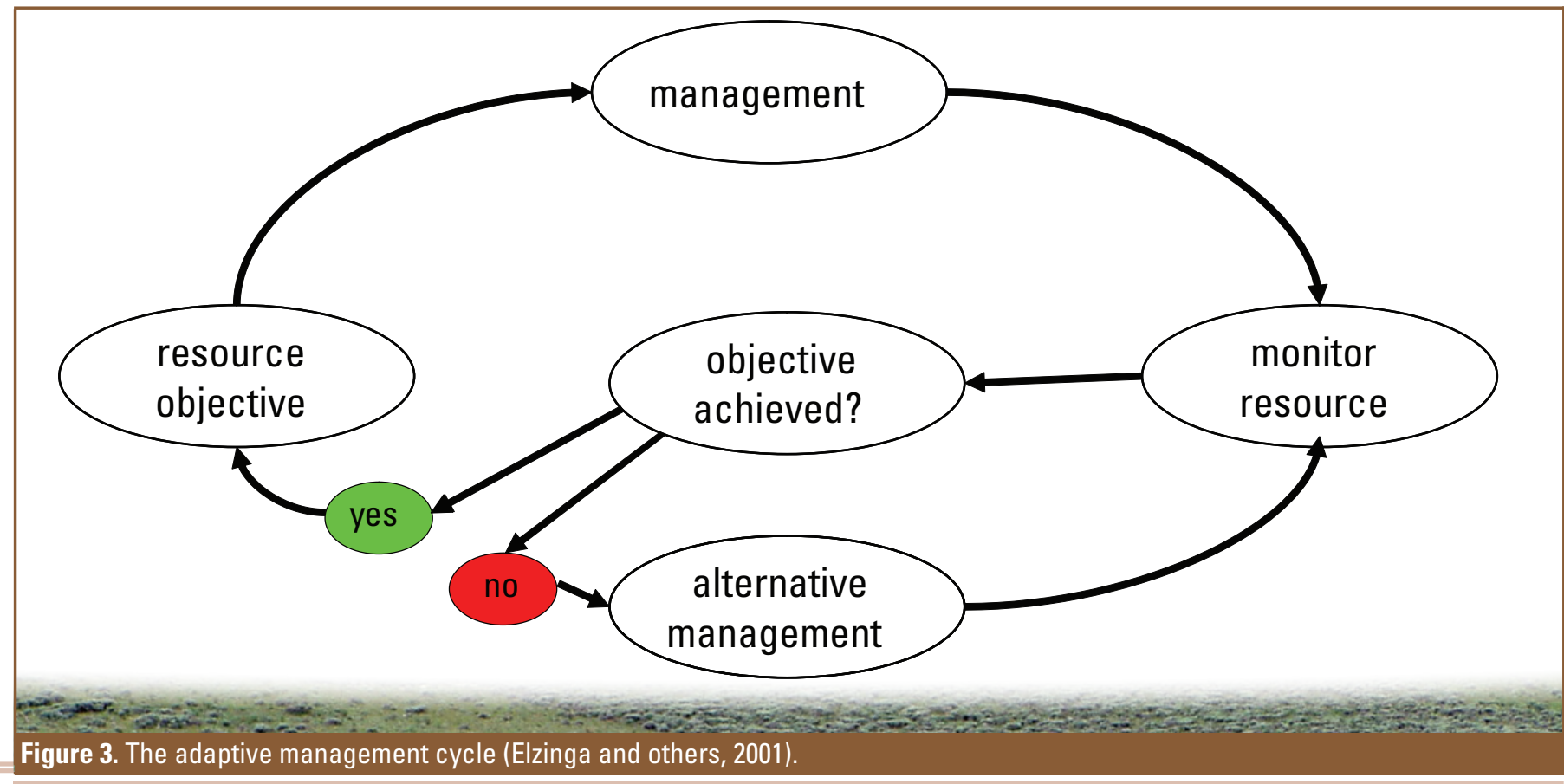


adjustments to management actions, interagency coordination will be essential; thus, USGS will endeavor to conduct research that can provide direct assistance to land managers who must evaluate potential management actions. Likewise, WLCI land management agencies will need to be flexible and responsive to research results for effective integration of science and management (adaptive management) to be achieved.

Many Federal, State, and local agencies, as well as nongovernmental organizations, have developed assessment and monitoring frameworks to quantify change and support adaptive management. In a recent project designed to develop an efficient and effective process for monitoring the health of lands administered by the BLM, Kotliar and others (2008) reviewed agency (BLM, FWS, USFS, NPS, and others) approaches to assessment and monitoring. The authors went on to develop a three-phase research and monitoring plan that has been coopted herein as the research and monitoring approach for the WLCI. Questions subsequently addressed by that plan are consistent with the WLCI management needs, including the need to evaluate the effects of anthropogenic and natural changes, energy development, and management actions.

\section{Developing a Framework for Conducting WLCI Science}

For WLCI science, an iterative three-phase approach is proposed, with successive stages building on the information and experience gained from earlier stages. With each phase, the research and monitoring program will be gradually expanded, beginning with an initial emphasis on greater use of existing data, spatial analysis, and predictive modeling, and ending with a fully integrated and coordinated program in the third phase. This three-phased approach allows for rapid implementation of a program to identify gaps and assess status and trends while gradually expanding the scope through feedback from an adaptive monitoring framework linked to WLCI objectives (fig. 4).

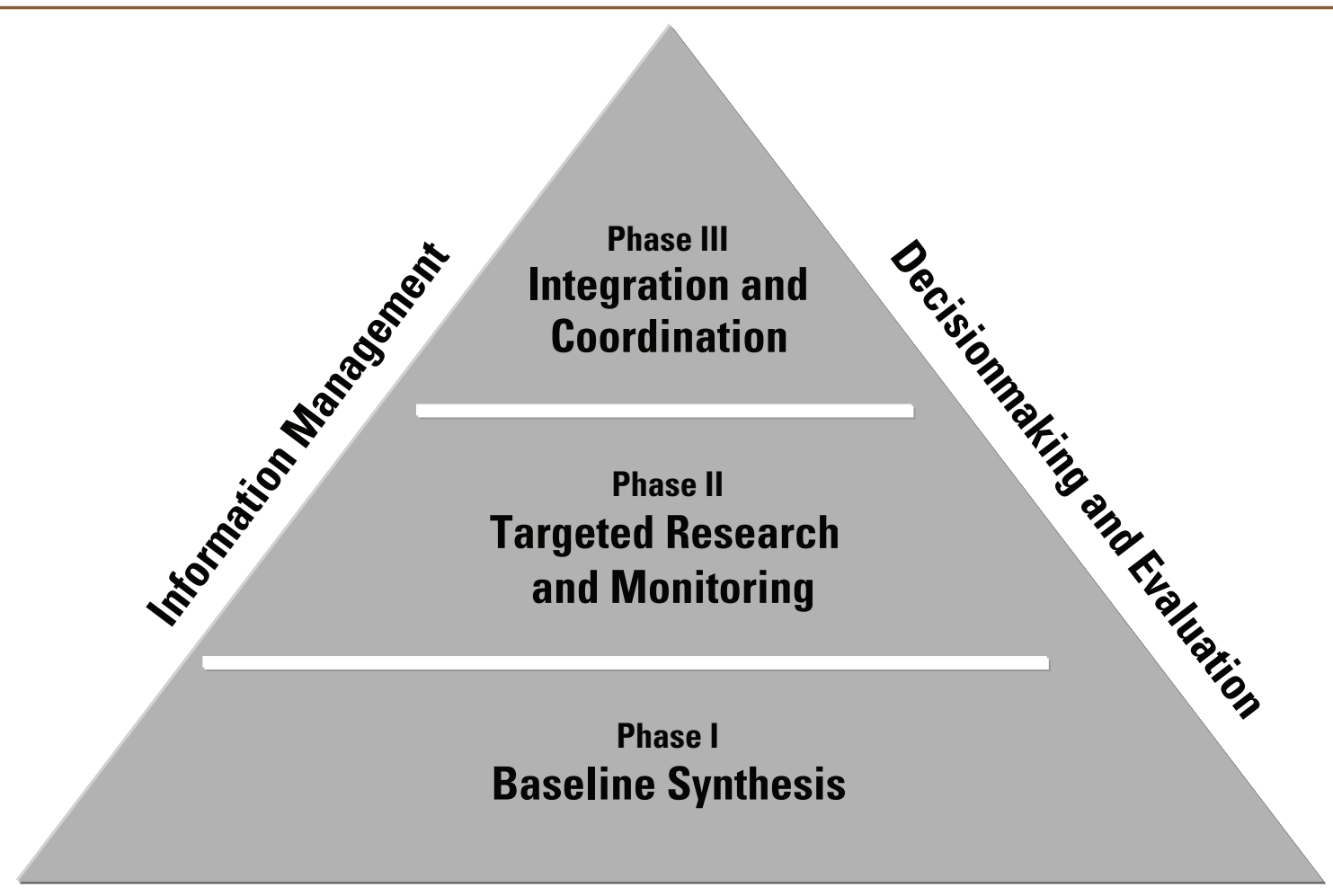

Management Needs
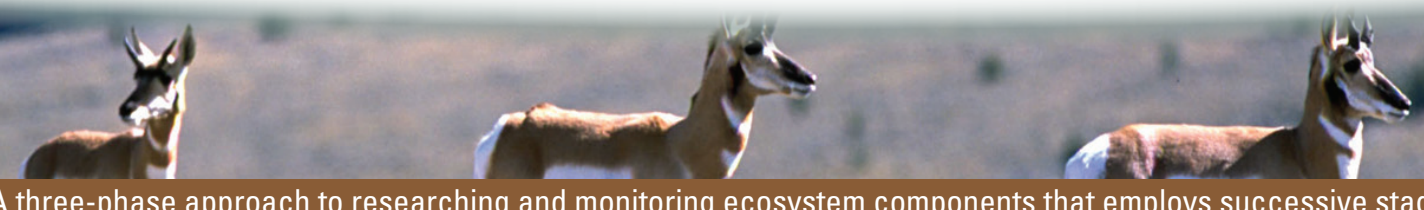

Figure 4. A three-phase approach to researching and monitoring ecosystem components that employs successive stages to build on information gained from earlier stages. The approach may be used iteratively and allows for stages to overlap. 
In Phase I, a baseline synthesis will be conducted by (1) capitalizing on existing data that are not being used currently, or are being used but may not be fully integrated; (2) incorporating existing habitat models into management decisionmaking and research design; (3) addressing landscapelevel cumulative effects of surface disturbance by using spatial analysis and GIS capabilities; and (4) identifying critical information gaps that require additional surveys, models, and(or) research. Phase I also will provide an initial assessment of the current status and trends of energy development and other stressors, their cumulative effects on wildlife, an indepth evaluation of the current state of knowledge and data quality, and a literature review to better understand the human dimensions of southwest Wyoming.

Phase II will entail the data collection process, relying on information provided in Phase I to refine management objectives and provide a linkage to management decisions through targeted monitoring, adaptive management, and research. Additionally, Phase II will expand the predictive modeling component developed in Phase I by modifying or creating habitat models for priority species based on new data, and by adding or expanding surveys and research to test predictions, assumptions, and critical information gaps identified in Phase I.

Phase III will help establish regional, State, and national priorities, strategies, and guidelines for monitoring that will be based, in part, on information derived from the application of Phases I and II to determine common priorities among WLCI partners. Combined effort of WLCI partners and collaborators will improve the efficiency and effectiveness of research and monitoring programs by reducing duplication of efforts and creating standard monitoring protocols for priority management issues that span multiple jurisdictional boundaries (for example, field offices, agencies) and provide for landscape-scale analyses.

Collectively, the three phases are designed to ensure that data and knowledge gaps are addressed, quality information is available to meet monitoring objectives and requirements for program assessment, and a framework for coordination among many agencies is employed. Each phase is designed to be implemented based on the best available information, yet considerable uncertainty will continue to exist. Consequently, each phase should be viewed as an iterative step to be repeated, refined, updated, and expanded as knowledge improves. The phases were designed to build on the preceding phase(s) and complement one another; thus, the activities associated with each are not necessarily mutually exclusive, and it is recognized that work activities associated with different phases may occur simultaneously. For example, sage-grouse conservation programs may be in development at the national level while being implemented at State and local levels. In addition, because each phase follows the same framework, there is overlap in the types of activities (modeling, for example) used to achieve the objectives of each phase.
The iterative process will facilitate the rapid implementation of high-priority work while allowing for a gradual expansion of research and monitoring with subsequent iterations. Additionally, it will avoid prohibitive startup costs and time-consuming background preparation required to implement a complex and comprehensive research and monitoring program; thus, a particular effort may address only the highest priority objectives in the initial implementation of the Strategy if there are constraints on funding, time, and knowledge. This approach is designed to allow maximum flexibility to meet a variety of resource-management issues.

\section{Implementation of the USGS WLCI Science Strategy}

The USGS WLCI Science Strategy is structured to match, as closely as possible, the needs and priorities of the WLCI. A full-time USGS employee has been dedicated to the WLCI Coordination Team to assist with ongoing needs for technical assistance and to participate in selecting and coordinating BLM habitat-improvement projects implemented in 2007 and beyond. Because habitat projects must follow National Environmental Policy Act requirements, generally BLMfunded WLCI projects for 2007 and 2008 were developed previously and lacked a funding source. Beginning with 2009 projects, project selection will be based more explicitly on WLCI objectives and requirements. The vision for future funding years is to fully incorporate available science and WLCI objectives early in the project development process.

The initial actions outlined in the Strategy (and detailed in the annual scope of work document) address immediate needs identified by WLCI members and will support the identification, implementation, and tracking of habitat projects in priority areas. In developing research and monitoring approaches to support the WLCI, the Science Team will integrate existing data and ongoing work, initiate additional data collection to address management needs (evaluating BMPs and restoration methods, for example), implement monitoring to assess the effectiveness of 2007-08 habitat projects, plan and initiate monitoring to assess change over multiple years, coordinate and integrate with other monitoring programs, and work towards development of a generalized model for conducting integrated assessments that can be applied to other geographic areas facing similar development pressures. The successful implementation of the Strategy and, in large measure, the success of the WLCI, will depend on the coordination and integration of people, ideas, and work.

Work conducted in 2008-09 will focus on the immediate WLCI needs and, more broadly, initiate the first phases of the overall research and monitoring approach. Activities will entail monitoring habitat-improvement and 
restoration projects, evaluating and integrating existing data, incorporating habitat and landscape models, and identifying and initiating studies to address priority data gaps and research questions. This work will be supported by ongoing studies, including existing USGS monitoring efforts and multiple interdisciplinary studies, such as the inventory of sagebrush communities throughout Wyoming. The specific work plan for each year will be detailed in a separate document.

\section{Anticipated Products for 2008-09}

- Conceptual models of ecosystem function and anthropogenic stressors, focusing on energy and climate as key drivers

- Refined list of key indicators (potentially biotic and(or) abiotic) for the WLCI

- Framework for assessing management activities and integrated long-term monitoring

- Pretreatment and posttreatment assessments for 07-08 management activities

- Initial comprehensive spatial analysis of key resources (for example, mule deer winter habitat) and existing/ projected development for prioritizing management and research

- Data-management framework

- Spatially explicit project-tracking system for WLCI

- Spatial data warehouse

- General reference maps

- Education and outreach Web site

- Summary report of the 2009 WLCI partner science workshop

\section{Coordination and Cooperative}

\section{Research}

The Strategy acknowledges the value of cooperative efforts and the need to promote collaboration in sharing and integrating data and information generated by all WLCI partners and collaborators. Collaboration with Federal, State, local, and nongovernmental organizations will generate multiple benefits for addressing research needs. USGS scientists will work with WLCI partners and their clients to generate relevant research and monitoring data that forms the basis for sound resource management decisions. New methods and technologies can be shared and integrated into scientific activities; specialized technical expertise can be leveraged to help support different projects; costs can be shared; and scientific findings and recommendations can be more effectively and efficiently communicated to resource managers and the public. These alliances require cooperation and regular communication to establish priorities, plan and conduct joint studies, and disseminate information, data, and reports.

Science Team members intend to use various strategies for promoting and fostering collaboration with WLCI partners, including (1) supporting data-collection efforts and minimizing duplication of effort; (2) supporting better integration of data across taxa and ecological and geographic scales; (3) identifying new research and information needs; (4) promoting and integrating new methodologies, analytical techniques, and protocols; (5) supporting existing monitoring activities; (6) enhancing the ability to predict, assess, and report the status and trends of biological resources in southwest Wyoming; and (7) supporting information outreach and developing information infrastructure for data generators and data users. Various activities already initiated exemplify these seven strategies. For example, USGS scientists have built an Access database (a "science catalog") for dissemination among partners and collaborators sharing results and products of science activities already completed (see http://www.wlci. gov/data.htm and click on "USGS Scientific Data Catalog Prototype"). By providing this opportunity for WLCI partners and collaborators to see what has already been accomplished, it is anticipated that this catalog will go a long way towards eliminating duplication of effort. Periodically, there have been and will continue to be meetings with BLM and other partners to identify annual priorities for new research and information needs. An initial effort to integrate methodologies entailed the requirement that all WLCI partners enter their research and monitoring protocols onto the WLCI Web site by October 2008. In support of existing monitoring activities, USGS scientists are currently scaling existing monitoring protocols from the local to the landscape scale. As a final example of the coordination and cooperation strategies outlined in this report, the USGS Geospatial Information Office (GIO) is leading an effort to create a Web-based toolkit that will serve as the foundation for integrating the information needed to support science and decisionmaking; this task includes designing the overall infrastructure as well as building the project's core tools, including forums, content-management tools, a document library, and community-specific wikis and blogs.

Finally, it should be emphasized that the science activities outlined herein are not intended to be the only science conducted for the WLCI; thus, coordination among research entities will be paramount. The Science Team will be working closely with the WLCI STAC to ensure that USGS activities complement and enhance new and existing efforts, identify and prioritize changing science needs, leverage technical expertise, provide scientific support for conservation and habitat enhancement projects, and effectively disseminate 
information to WLCI partners, collaborators, and the general public. This collaboration will result in a more comprehensive and efficient information base from which managers can conduct planning and make operational decisions, thereby strengthening adaptive monitoring and management.

\section{Education, Outreach, and Community Involvement}

A crucial aspect of the WLCI and the research supporting this initiative is to conduct work that is useful and important to people who live in southwest Wyoming. To ensure that people in the WLCI area are informed and involved in the initiative, WLCI members have formed a communication and outreach team. Early in the development of the initiative, this team organized open house meetings at each BLM Field Office in southwest Wyoming to introduce the WLCI to the public. As the initiative evolves, this outreach effort will grow.

Education and outreach will include efforts to communicate work plans for habitat-improvement projects and research findings to various groups and individuals. These efforts will involve general and targeted communications through Web sites, print media, and presentations - in schools, with stakeholder groups, or at public meetings. Education and outreach meetings will allow stakeholders and the public to provide feedback on the WLCI. Community involvement is required for success of the WLCI, as all of the habitatimprovement projects will involve public or private lands used or owned predominantly by the citizens of southwest Wyoming. Citizens also will be active participants in defining and conducting individual habitat projects.

Part of USGS's involvement in the WLCI will entail providing education and outreach on the WLCI Web site, as well as Internet-based public access to data, relevant literature, and research products. The existing WLCI Web site (http:// www.wlci.gov/) will be enhanced to serve as an educational tool to be used by scientists, land managers, industry, and the public. In addition to developing and hosting a multipurpose Web site for disseminating information, USGS will produce an annual report on WLCI science and technical assistance activities. The report will be provided to all WLCI member agencies and posted for distribution on the WLCI Web site. As part of the community involvement program related to science activities, USGS will host field and site visits for interested groups to provide a first-hand look at the project work and science of the WLCI.

\section{References Cited}

Berger, J., 2004, The last mile-how to sustain long-distance migration in mammals: Conservation Biology, v. 18, p. 320-329.

Clark T.W., and Stromberg, M.R., 1987, Mammals in Wyoming: Lawrence, Kans., University of Kansas Museum of Natural History, Publication Education Series 10, p.1-314.

Connelly, J.W., Knick, S.T., Schroeder, M.A., and Stiver, S.J., 2004, Conservation assessment of greater sage-grouse and sagebrush habitats: Cheyenne, Wyo., Western Association of Fish and Wildlife Agencies, accessed March 2007 at http://www.ndow.org/wild/conservation/sg/resources/ greate_sg_cons_assessment.pdf.

Davis, M.B., and Shaw, R.G., 2001, Range shifts and adaptive responses to Quaternary climate change: Science, v. 292, no. 5517 , p. 673-679.

D'Erchia, F., editor, 2008, Wyoming Landscape Conservation Initiative workshop proceedings, May 15-17, 2007: U.S. Geological Survey Scientific Investigations Report 20085073, 96 p., available at http://pubs.usgs.gov/sir/2008/5073/.

Elzinga, C.L, Salzer, D.W., Willoughby, W.J., and Gibbs, P.J., 2001, Monitoring plant and animal populations: Malden, Mass., Blackwell Science, Inc.

Freilich, J., Budd, B., Kohley, T. Hayden, B., 2001, Wyoming Basins ecoregional plan: Lander, Wyo., The Nature Conservancy.

Holloran, M.J., 2005, Greater sage-grouse (Centrocercus urophasianus) population response to natural gas field development in western Wyoming: Laramie, Wyo., Ph.D. dissertation, University of Wyoming.

Heemskerk, M., Wilson, K., and Pavao-Zuckerman, M., 2003, Conceptual models as tools for communication across disciplines: Conservation Biology, v. 7, no. 3, p. 8, available at http://www.consecol.org/vol7/iss3/art8.

Interagency Wyoming Landscape Conservation Initiative Planning Group, 2006, Wyoming landscape conservation initiative concept paper: Interagency Wyoming Landscape Conservation Initiative Planning Group, accessed July 2007 at http://www.wlci.gov/docs/WLCI_ConceptPaper.pdf. 
Kiesecker, J.M., Copeland, H.E., Pocewicz, A., McKenney, B., Stroud, D., Dahlke, J., Holloran, M., and Nibblelink, N., 2009, A framework for implementing biodiversity offsetsselecting sites and determining scale: Bioscience, V. 59 p. 77-84.

Knight, D.H., 1994, Mountains and plains - the ecology of Wyoming landscapes: New Haven, Conn., Yale University Press, 338 p.

Kotliar, N., Bowen, Z. Ouren, D., and Farmer, A., 2008, A regional approach to wildlife monitoring related to energy exploration and development in Colorado: U.S. Geological Survey Open-File Report 2008-1024, 66 p.

Krummel, J.R., and LaGory, K.E., 2004, North Slope science initiative - a strategy for inventory, monitoring, and research, draft: Argonne, Ill., Argonne National Laboratory, Environmental Assessment Division.

Mackey, M., 1997, Black gold-patterns in the development of Wyoming's oil industry: Powell, Wyo., Western History Publications.

Neely, B., Comer, P., Moritz, C., Lammert, M., Rondeau, R., Pague, C., Bell, G., Copeland, H., Humke, J., Spackman, S., Schulz, T., Theobald, D., and Valutis, L., 2001, Southern Rocky Mountains - an ecoregional assessment and conservation blueprint: Boulder, Colo., The Nature Conservancy; U.S. Department of Agriculture, Forest Service, Rocky Mountain Region; Colorado Division of Wildlife; and DOI Bureau of Land Management.

Neilson, R.P., Lenihan, J.M., Bachelet, D., and Drapek, R.J., 2005, Climate change implications for sagebrush ecosystems: Transactions of the North American Wildlife and Natural Resources Conference, v. 70, p. 145-159.

Nichols, J.D., and Williams, B.K., 2006, Monitoring for conservation: Trends in Ecology and Evolution, v. 21, no. 12, p. 668-673.

Noss, R., Wuerthner, G., Vance-Borland, K., and Carroll, C., 2001, A biological conservation assessment for the Utah-Wyoming-Rocky Mountains Ecoregion-a report to The Nature Conservancy: Corvallis, Oreg., Conservation Science, Inc.

Orians, G., Albert, T., Brown, G., Cameron, R., Cochran, P., Gerlach, S.C., Gramling, R., Gyrc, G., Hite, D., Kennicutt, M., II, Lachenbruch, A., Lowry, L., Moulton, L., Pielou, C., Sedinger, J., Lindstedt-Siva, K.J., Speer, L., and Walker, D., 2003, Cumulative environmental effects of oil and gas development activities on Alaska's North Slope: Washington, D.C., National Academic Press.
Rowland, M.M., Leu, M., Hanser, S., Finn, S.P., Aldridge, C.L., Knick, S.T., Suring, L.H., Boyd, J.M., Wisdom, M.J., and Meinke, C.W., 2006, Assessment of threats to sagebrush habitats and associated species of concern in the Wyoming Basins, version 2.0: Boise, Idaho, U.S. Geological Survey, Biological Resources Discipline, Snake River Field Station, available at http://www.nrel.colostate.edu/ aldridge/_ documents/WBEA_Chapters\%20v2.0_March\%202006.pdf and http://www.nrel.colostate.edu/ aldridge/_documents/ WBEA_Appendices\%20v2.0_March\%202006.pdf.

Russell, E.W.B., 1997, People and the land through timelinking ecology and history: New Haven, Conn., Yale University Press, 306 p.

Sawyer, H., Lindzey, F., McWhirter, D., 2005, Mule deer and pronghorn migration in western Wyoming: Wildlife Society Bulletin, v. 33, no. 4, p. 1266-1273.

Sawyer, H., Lindzey, F., McWhirter, D., and Andrews, K., 2002, Potential effects of oil and gas development on mule deer and pronghorn populations in western Wyoming: Transactions of the North American Wildlife and Natural Resources Conference, v. 67, p. 350-365.

Sawyer, H., Nielson, R.M., Lindzey, F., and McDonald, L.L., 2006, Winter habitat selection of mule deer before and during development of a natural gas field: Journal of Wildlife Management, v. 70, no. 2, p. 396-403.

TRC Mariah Associates, Inc., 2005, Draft socioeconomic analysis technical document for the Jonah Infill Drilling and South Piney Projects environmental impact statements: Laramie, Wyo., TRC Mariah Associates, Inc., prepared for Bureau of Land Management, Wyoming State Office, Pinedale Field Office, and Jonah Infill Drilling Project Operators.

Turner, B.L., II, Clark, W.C., Kates, R.W., Richards, J.F., Mathews, J.T., and Meyer, W.B., eds., 1990, The Earth as transformed by human action-global and regional changes in the biosphere over the past 300 years: Cambridge, England, Cambridge University Press, 713 p.

U.S. Bureau of Land Management, 2008, Environmental impact statement for the Pinedale Resource management plan for public lands administered by the Bureau of Land Management Pinedale Field Office, Pindedale, Wyoming: Pinedale, Wyo., U.S. Department of Interior, Bureau of Land Management, Pinedale Field Office, in cooperation with the State of Wyoming, Sublette County, Sublette County Conservation District, Lincoln County, Lincoln County Conservation District, and Environmental Protection Agency, available at http://www.blm.gov/rmp/wy/pinedale/ documents.html. 
U.S. Department of Energy, 2004, Annual energy outlook 2004 with projections to 2025: accessed July 2007 at $h t t p: / /$ www.eia.doe.gov/oiaf/aeo/gas.html.

U.S. Departments of the Interior, Agriculture, and Energy, 2006, Scientific inventory of onshore Federal Lands' oil and gas resources and the extent and nature of restrictions or impediments to their development, Phase II inventory report: BLM/WO/GI-03/002+3100/REV06, 344 p., accessed March 2007 at $h t t p: / / w w w . b l m . g o v / e p c a /$.

U.S. Geological Survey, 2007, Facing tomorrow's challenges-U.S. Geological Survey science in the decade 2007-2017: U.S. Geological Survey Circular 1309, x + 70 p., accessed March 2007 at http://pubs.usgs.gov/ circ/2007/1309/.

Wyoming Game and Fish Department, 2003, Wyoming greater sage-grouse conservation plan: Wyoming Game and Fish Department, accessed July 2007 at http://gf.state.wy.us/ wildlife/wildlife_management/sagegrouse.asp.

Wyoming Game and Fish Department, 2005, A comprehensive wildlife conservation strategy for Wyoming: Cheyenne, Wyo., Wyoming Game and Fish Department, available at http://gf.state.wy.us/wildlife/CompConvStrategy/. 
